\section{SANDIA REPORT}

SAND94-0878 - UC-910

Unlimited Release

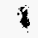

Printed August 1994
Kas

Oefo 3 198.

$08 \mathrm{TI}$

\title{
Effect of Phase Change in a Debris Cloud on a Backwall Structure
}

\author{
L. N. Kmetyk, L. C. Chhabildas, M. B. Boslough, R. J. Lawrence
}

\section{Prepared by}

Sandla National Laboratorles

Albuquerque, New Mexlco 87185 and Llvermore, California 94550

for the United States Depertment of Energy

under Contract DE-ACO4-94AL85000

Approved for public release; distribution is unlimited.
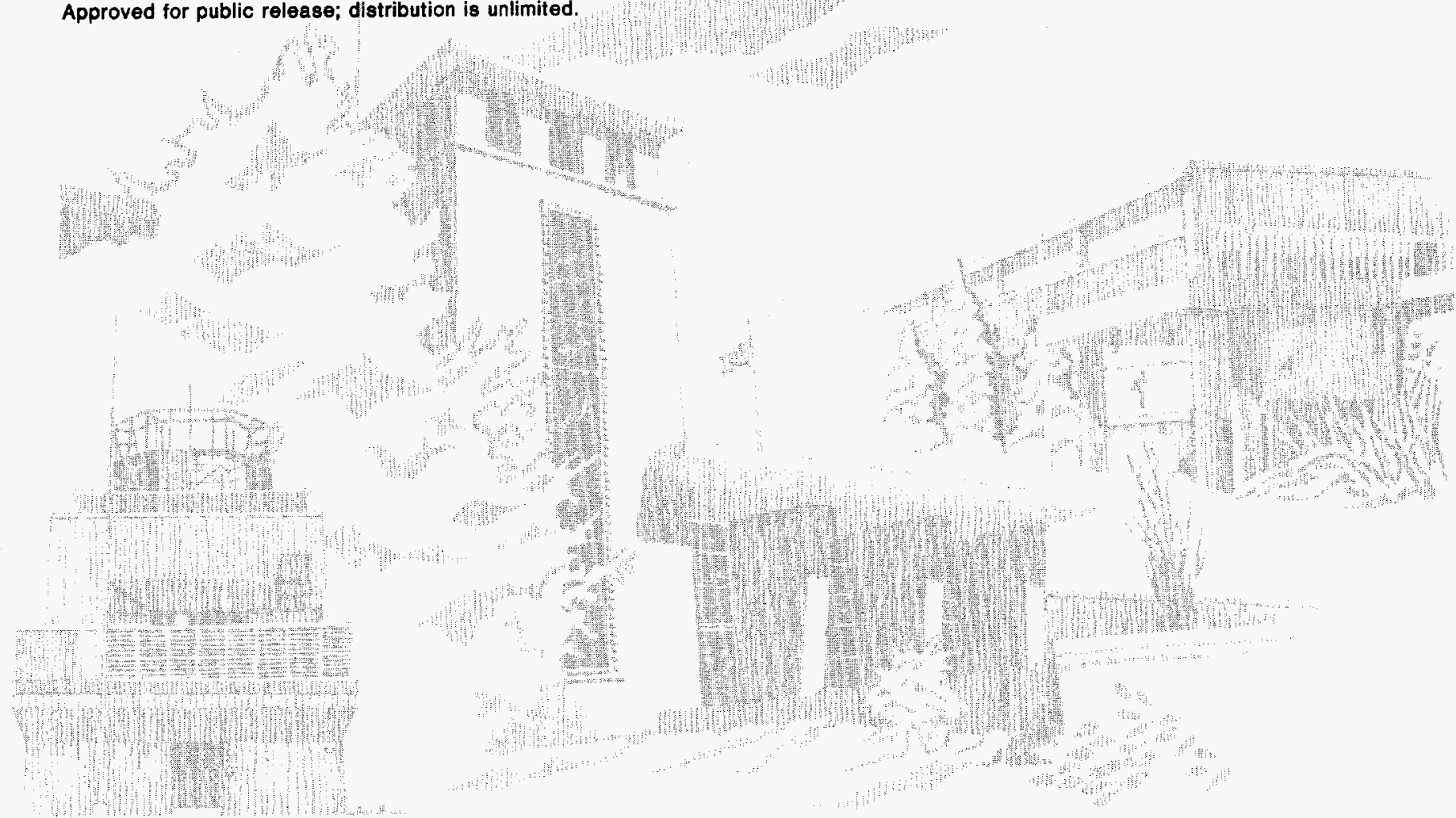
Issued by Sandia National Laboratories, operated for the United States Department of Energy by Sandia Corporation.

NOTICE: This report was prepared as an account of work sponsored by an agency of the United States Government. Neither the United States Government nor any agency thereof, nor any of their employees, nor any of their contractors, subcontractors, or their employees, makes any warranty, express or implied, or assumes any legal liability or responsibility for the accuracy, completeness, or usefulness of any information, apparatus, product, or process disclosed, or represents that its use would not infringe privately owned rights. Reference herein to any specific commercial product, process, or service by trade name, trademark, manufacturer, or otherwise, does not necessarily constitute or imply its endorsement, recommendation, or favoring by the United States Government, any agency thereof or any of their contractors or subcontractors. The views and opinions expressed herein do not necessarily state or reflect those of the United States Government, any agency thereof or any of their contractors.

Printed in the United States of American. This report has been reproduced directly from the best available copy.

Available to DOE and DOE contractors from

Office of Scientific and Technical Information

PO Box 62

Oak Ridge, TN 37831

Prices available from (615) 576-8401, FTS 626-8401

Available to the public from

National Technical Information Service

US Department of Commerce

5285 Port Royal RD

Springfield, VA 22161

NTIS price codes

Printed copy: A04

Microfiche copy: A06 


\section{DISCLAIMER}

Portions of this document may be illegible in electronic image products. Images are produced from the best available original document. 
Distribution

Category UC-910

SAND94-0878

Unlimited Release

Printed June 1994

\title{
Effect of Phase Change in a Debris Cloud on a Backwall Structure
}

\author{
L. N. Kmetyk \\ Thermal/Hydraulic Analysis Department \\ L. C. Chhabildas, M. B. Boslough \\ Experimental Impact Physics Department \\ R. J. Lawrence \\ Computational Physics Research and Development Department \\ Sandia National Laboratories \\ Albuquerque, NM 87185
}

\begin{abstract}
The physical state of a debris cloud generated upon impact of a thin flier plate with a thin bumper depends on the impact velocity and material properties. At inpact velocities of $10 \mathrm{~km} / \mathrm{s}$, the debris cloud is expected to be primarily molten with some vapor present. A series of calculations using the finite-difference code CTH has been used to evaluate the effect of phase change (i.e., higher concentrations of vapor) in debris clouds and their subsequent impact on a backwall structure. In these calculations, the higher concentration of vapor is achieved artificially by increasing the initial temperature of the impactor and the bumper material while keeping the same impact velocity. The nature of the interaction of the debris cloud with, and the subsequent loading of, the backwall depends on the thermophysical state of the debris cloud. This interaction (with a backwall) can cause either spallation, rupture, or simply bulging of the backwall structure. These results will be discussed and compared with an impact experiment performed at $\sim 10 \mathrm{~km} / \mathrm{s}$ on the Sandia hypervelocity launcher. In the experiment, the debris cloud was generated by the impact of a titanium plate with a titanium bumper.
\end{abstract}





\section{Contents}

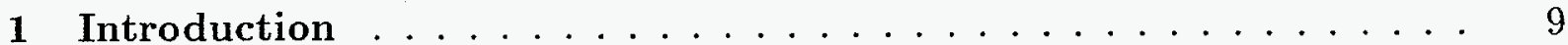

2 Experimental Technique and Results . . . . . . . . . . . . 11

3 CTH Input Model . . . . . . . . . . . . . . . . . . . . . . . . . . 14

3.1 Bumper Impact . . . . . . . . . . . . . . . . . . . . . 14

3.2 Backwall Impact $\ldots \ldots \ldots \ldots \ldots \ldots$

4 Basecase Results . . . . . . . . . . . . . . . . . . 16

5 Variational Studies . . . . . . . . . . . . . . . . . 24

5.1 Initial Temperature Variations . . . . . . . . . . . . . . 24

5.2 Impact Velocity Variations . . . . . . . . . . . . . . . . 27

5.3 Bumper Material Variations . . . . . . . . . . . . . . . . . 34

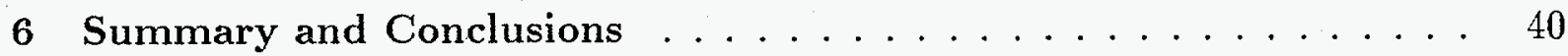

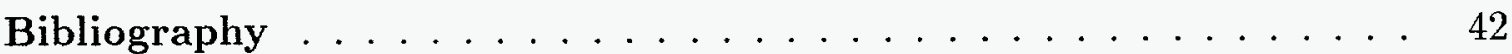

A Bumper-Impact Input Deck . . . . . . . . . . . . . . . . . . 44

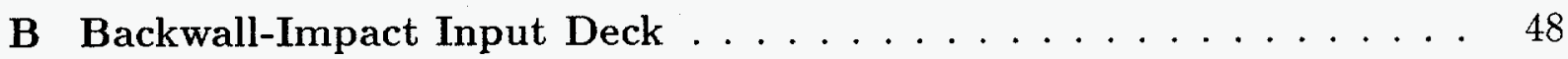




\section{List of Figures}

2.1 Experimental Impact Configuration used to Simulate Orbital Debris Impact on a Whipple Bumper Shield Design . . . . . . . . . . . . .

2.2 Radiograph (Top) and Photograph (Bottom) of Debris Cloud Generated in

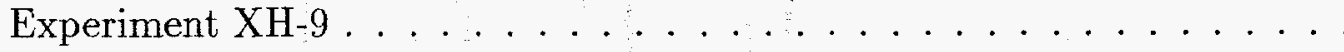

4.1 Debris Cloud at $1 \mu \mathrm{s}$ (upper left), $2 \mu \mathrm{s}$ (upper right), $3 \mu \mathrm{s}$ (lower left), and $4 \mu \mathrm{s}$ (lower right) for Base Case Calculation . . . . . . . . . . 17

4.2 Debris Cloud at $5 \mu$ s for Base Case Calculation . . . . . . . . . 18

4.3 Debris Cloud at $6 \mu$ s for Base Case Calculation . . . . . . . . . . 19

4.4 Debris Cloud and Backwall Structure at 10 $\mu$ s (upper left), $15 \mu$ s (upper right), $20 \mu \mathrm{s}$ (lower left), and $25 \mu \mathrm{s}$ (lower right) for Base Case Calculation .

4.5 Backwall Structure at $35 \mu$ s for Base Case Calculation . . . . . . . . . 21

4.6 Pressure on Backwall for Base Case Calculation . . . . . . . . . . . 22

4.7 Impulse on Backwall for Base Case Calculation . . . . . . . . . . 23

5.1.1 Debris Cloud at $5 \mu$ s for Base Case Calculation (upper left), "Hot-Bumper" (upper right), "Hot" (lower left) and "Very-Hot" (lower right) Initial Temperature Variations . . . . . . . . . . . . . . . .

5.1.2 Pressure on Backwall at Radial Distance of 0 (upper left), 0.2cm (upper right), $0.4 \mathrm{~cm}$ (lower left) and $0.6 \mathrm{~cm}$ (lower right) for Base Case Calculation and Initial Temperature Variations . . . . . . . . . . . . . . .

5.1.3 Impulse on Backwall at Radial Distance of 0 (upper left), $0.2 \mathrm{~cm}$ (upper right), $0.4 \mathrm{~cm}$ (lower left) and $0.6 \mathrm{~cm}$ (lower right) for Base Case Calculation and Initial Temperature Variations . . . . . . . . . . . . .

5.1.4 Backwall Configuration at $35 \mu$ s for Base Case Calculation (upper left), "Hot-Bumper" (upper right), "Hot" (lower left) and "Very-Hot" (lower right) Initial Temperature Variations . . . . . . . . . . . . . . .

5.2.1 Debris Cloud at $2.5 \mu \mathrm{s}$ for $20 \mathrm{~km} / \mathrm{s}$ Impact (top) and at $1.6 \mu \mathrm{s}$ for $30 \mathrm{~km} / \mathrm{s}$ Impact (bottom) . . . . . . . . . . . . . .

5.2.2 Pressure on Backwall at Radial Distance of 0 (upper left), $0.2 \mathrm{~cm}$ (upper right), $0.4 \mathrm{~cm}$ (lower left) and $0.6 \mathrm{~cm}$ (lower right) for Base Case Calculation and Impact-Velocity Variations . . . . . . . . . . . . . . .

5.2.3 Impulse on Backwall at Radial Distance of 0 (upper left), 0.2cm (upper right), $0.4 \mathrm{~cm}$ (lower left) and $0.6 \mathrm{~cm}$ (lower right) for Base Case Calculation and Impact-Velocity Variations . . . . . . . . . . . . . . . . .

5.2.4 Backwall Configuration at $35 \mu \mathrm{s}$ for $20 \mathrm{~km} / \mathrm{s}$ Impact (top) and for $30 \mathrm{~km} / \mathrm{s}$

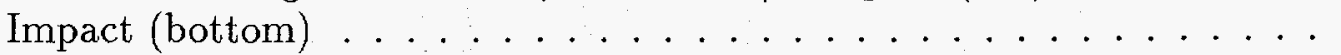


5.3.1 Debris Cloud at $5 \mu$ s for Cadmium Bumper Shield (top) and for Plastic Bumper Shield (bottom) . . . . . . . . . . . . . . .

5.3.2 Pressure on Backwall at Radial Distance of 0 (upper left), $0.2 \mathrm{~cm}$ (upper right), $0.4 \mathrm{~cm}$ (lower left) and $0.6 \mathrm{~cm}$ (lower right) for Base Case Calculation and Bumper-Material Variations $\ldots \ldots \ldots \ldots \ldots \ldots$

5.3.3 Impulse on Backwall at Radial Distance of 0 (upper left), $0.2 \mathrm{~cm}$ (upper right), $0.4 \mathrm{~cm}$ (lower left) and $0.6 \mathrm{~cm}$ (lower right) for Base Case Calculation and Bumper-Material Variations $\ldots \ldots \ldots \ldots \ldots$

5.3.4 Backwall Configuration at 35 $\mu$ s for Cadmium Bumper Shield (top) and for Plastic Bumper Shield (bottom) . . . . . . . . . . . . . . . . .

\section{List of Tables}

3.1 ANEOS Equation-of-State Parameters Used in CTH Base Case Calculation 15

5.1 Initial-Temperature Variation Study Input . . . . . . . . . . . 25

5.2 Bumper-Material Variation Study Input . . . . . . . . . . . . 25 


\section{Acknowledgements}

The authors wish to acknowledge the able technical assistance provided by W. D. Reinhart and C. A. Hall for the experiments. We would also like to thank N. T. Tsai and $\mathrm{J}$. Connell for providing the motivation and for their interest in this study. 


\section{Introduction}

It is well known that the principal threat to orbiting space structures results from impact damage caused by orbiting space debris [1,2]. Presently, conventional laboratory facilities are not available for evaluating damage mechanisms or the effectiveness of protective structures against this debris. Although analytic methods $[3,4]$ for predicting impact damage and hydrodynamics code [5] simulations of impact events have progressed to the point of providing realistic damage assessments, these analyses and/or models have not been validated over the velocity range of 7 to $10 \mathrm{~km} / \mathrm{s}$, primarily due to lack of experimental capabilities to launch gram-size plates or particles over that velocity range.

A requirement for an effective debris shield is that it must protect the spacecraft from impacts both from the micrometeoroid and orbital debris environment. The micrometeoroid environment is thought to result from dust-size particles having an average velocity of $20 \mathrm{~km} / \mathrm{s}$, while the orbital debris environment is believed to be millimeteror centimeter-size particles weighing approximately a gram with average velocities of $10 \mathrm{~km} / \mathrm{s}$. It is generally assumed that the average density of orbital debris in the environment $[1,2]$ is $\sim 2.8 \mathrm{~g} / \mathrm{cm}^{3}$, and therefore can be represented by the material properties of aluminum. The orbital debris, i.e., the man-made space debris, is more hazardous than the micrometeoroid environment because of its abundance and relatively large mass and particle size. This makes the design requirements for an adequate bumper shield difficult to establish. In addition, the requirements for an adequate bumper shield are demanding due to:

1. The uncertainty in the size, shape and density of the orbital debris particulates,

2. The inability of hydrodynamics codes to accurately represent impact phenomena due to uncertainties in material properties and computational difficulties associated with the propagation of fragmented (molten and partially vaporized) debris, and

3. The lack of an impact test capability with launcher mass-velocity capabilities of approximately a gram and in excess of $7 \mathrm{~km} / \mathrm{s}$ to test design concepts.

With the development of a hypervelocity launch capability $[6,7]$ at Sandia, it is now possible to perform experiments over the velocity range of 7 to $12 \mathrm{~km} / \mathrm{s}$ [8], a velocity range not previously accessible for gram-size plates. This approximates the mass-velocity criteria established for the orbital debris environment, but not the shape.

A previous study [9] summarized test results performed to evaluate the integrity of a simple aluminum Whipple bumper shield located at $114 \mathrm{~mm}$ from the space structure at impact velocities of $\sim 10 \mathrm{~km} / \mathrm{s}$; the mass of the aluminum flier plate, which is supposed to represent the orbital debris particle, was varied from $0.32 \mathrm{~g}$ to $1.3 \mathrm{~g}$. Numerical simulations of those experiments were performed using the Eulerian finite-difference code CTH [10], results of which are also summarized in that report [9]. Results of those experiments 
indicated that the thin aluminum bumper completely disintegrated into a debris cloud upon impact at $\sim 10 \mathrm{~km} / \mathrm{s}$ by the aluminum flier plate. The debris cloud front propagated at velocities in excess of $14 \mathrm{~km} / \mathrm{s}$, and expanded radially at a velocity of $\sim 7 \mathrm{~km} / \mathrm{s}$. Photographic techniques were used to determine the propagation characteristics of the debris clouds in these experiments. Subsequent loading on the hull structure by the debris cloud penetrated the substructure completely. However, when the mass of the flier plate was reduced to $0.32 \mathrm{~g}$ the substructure (although "damaged") was not punctured over the duration of the experiment. CTH simulations of those experiments predicted the results of the experiments qualitatively in that the penetration or lack of penetration of the substructure was correctly predicted; however, the propagation characteristics of the debris cloud were not replicated quantitatively.

In this report, test results performed to evaluate the integrity of a titanium-alloy Whipple bumper shield located at $152 \mathrm{~mm}$ from the space structure at impact velocities of $\sim 10 \mathrm{~km} / \mathrm{s}$ are presented, together with CTH simulations of this experiment; in this case, the mass of the titanium-alloy flier plate was $\sim 1 \mathrm{~g}$. This study determines the "mass" requirements of the orbital debris for the integrity of a backwall structure. It is the purpose of this report, however, to evaluate other methods to protect the backwall structure. This has led to an evaluation of the effect of increased vapor concentration in a debris cloud for a mixed mass of the orbital debris to protect a backwall structure. The results of this study are summarized in this report.

The experimental technique used to obtain hypervelocity launch characteristics has been described elsewhere [11]; the experimental setup used to simulate orbital debris impact conditions is described here only briefly, followed by a discussion and summary of the experimental results. The CTH input model is described briefly, followed by results of our basecase calculations with comparison to experimental data. Three computational sensitivity studies were done starting from that basecase, investigating the effect of initial temperature variations, impact velocity variations, and bumper material variations on debris cloud conditions and backwall damage. 


\section{Experimental Technique and Results}

The experimental technique used to obtain hypervelocity launch characteristics has been described elsewhere [11]. The experimental setup used to simulate orbital debris impact conditions is described here briefly, followed by a discussion and summary of the experimental results in the next section.

The experimental impact configuration used to simulate orbital debris impact is indicated in Figure 2.1. In experiment XH-9, a $1 \mathrm{~mm}$-thick, $12.7 \mathrm{~mm}$-diameter Ti-6Al-4V flier weighing about $0.53 \mathrm{~g}$ was launched to a velocity of $9.7 \mathrm{~km} / \mathrm{s}$. The flier impacted on a bumper consisting of a single sheet of $0.74 \mathrm{~mm}$-thick Ti-6Al-4V. A $4 \mathrm{~mm}$-thick backwall of $6061-\mathrm{T} 6$ aluminum was located about $150 \mathrm{~mm}$ beyond the bumper sheet.

The two principal diagnostic techniques that were used to characterize the impactgenerated debris cloud were 1) fast framing photography, and 2) flash x-ray radiography. The framing photography collects light reflected, scattered and radiated from the expanding debris cloud, whereas the flash x-ray images are exposed by $x$-rays that are not absorbed by the debris cloud. For this reason, the photographs tend to be sensitive to the low-density, hot, vapor part of the cloud, and the radiographs are sensitive to the higher-density material within the cloud. Combining these two complementary techniques provides a comprehensive set of image data that is necessary to characterize the impact-generated debris cloud.

Such data for experiment XH-9 are presented in Figure 2.2. The left-hand image is a flash $\mathrm{x}$-ray radiograph of the flier just before impact, showing it to be intact and slightly bowed. In the upper center is a flash x-ray image that was exposed about $5.8 \mu \mathrm{s}$ after impact. It is apparent that most of the mass in this image is moving in three narrow columns all parallel to the impact direction. In the lower center is depicted a framing camera image, also showing the debris cloud about $5.8 \mu$ s after impact. The central columnar streams of high-density material are no longer visible, but diffuse clouds of low-density vapor dominate the image. Note that the photographic debris cloud has propagated farther that the one imaged by the $\mathrm{x}$-ray debris cloud, indicating that the low-density vaporized debris front is travelling faster than the relatively higher-density cloud imaged using x-rays. Analysis of these images suggests that the leading edge of the debris cloud determined from photographic records is travelling at over $11 \mathrm{~km} / \mathrm{s}$, while the $\mathrm{x}$-ray radiograph yields a velocity of $\sim 10 \mathrm{~km} / \mathrm{s}$. (Similar results have been reported previously for aluminum flier plates impacting aluminum bumpers [12-18].) 

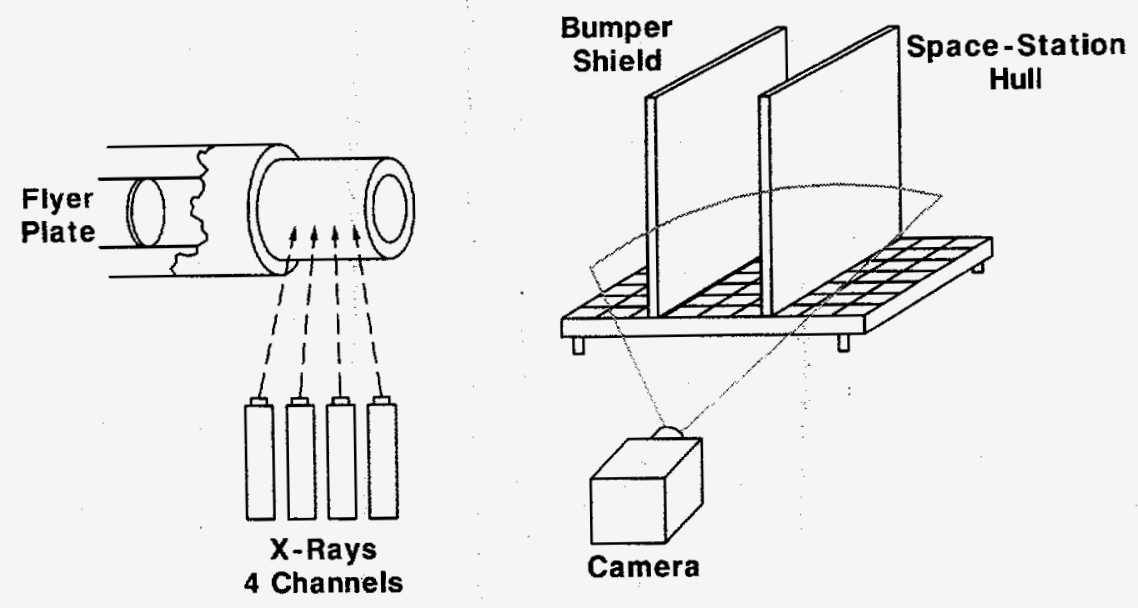

Figure 2.1. Experimental Impact Configuration used to Simulate Orbital Debris Impact on a Whipple Bumper Shield Design 


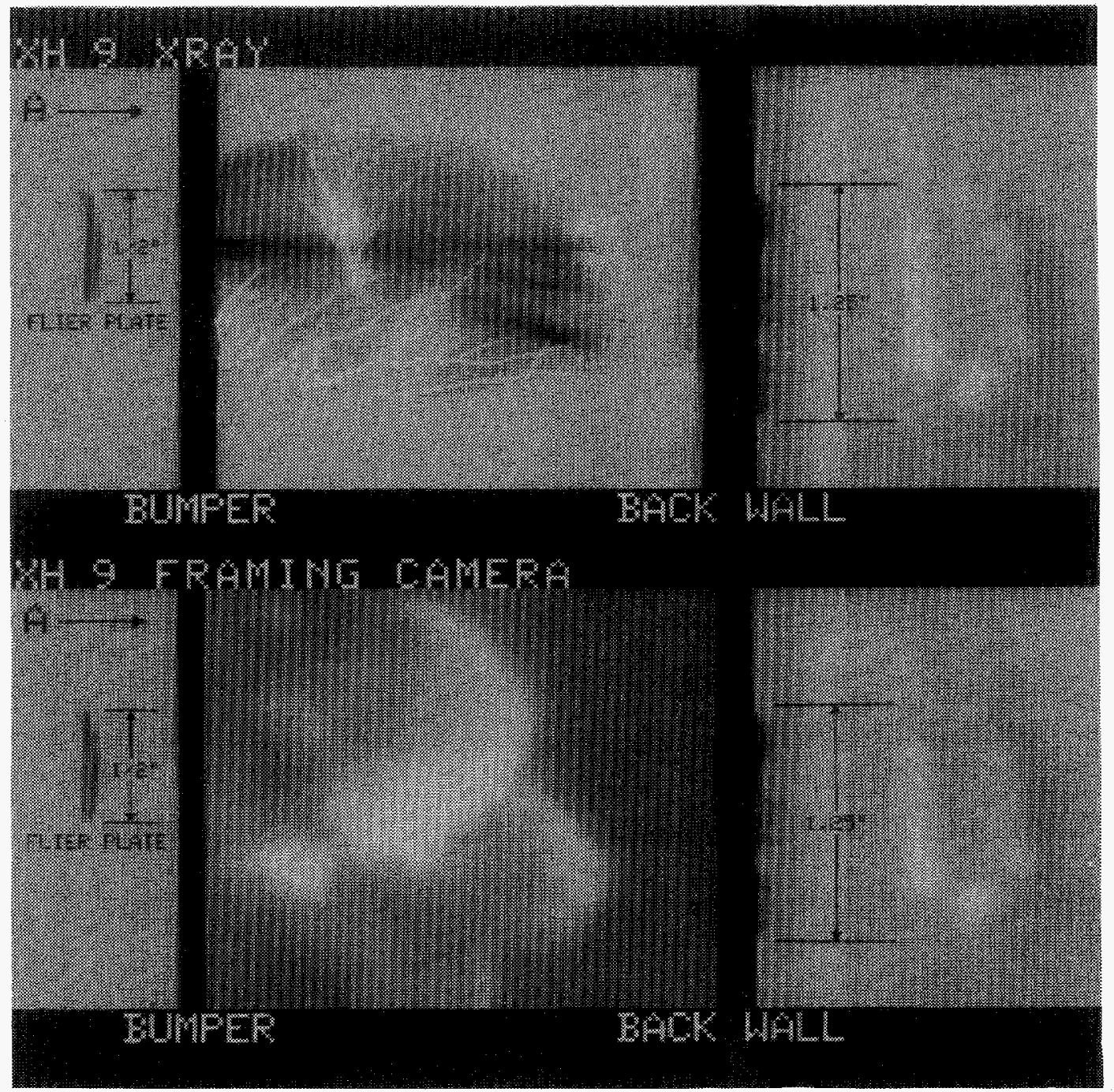

Figure 2.2. Radiograph (Top) and Photograph (Bottom) of Debris Cloud Generated in Experiment XH-9 


\section{CTH Input Model}

The CTH calculations were performed using a two-dimensional, cylindrical, geometry, and with the nonequilibrium, multi-material temperature and multi-material pressure modelling options and with the high-resolution interface tracker. Velocity was specified to be convected conserving momentum exactly and discarding any kinetic energy discrepancies. Artificial viscosity was used, with default values for the linear and quadratic coefficients, and the shear artificial viscosity increased to 0.1 . The region around the flier plate, bumper shield and backwall was modelled as void.

The flier plate, bumper shield and backwall were all specified to be modelled by ANEOS equations of state [19], and as elastic-perfectly plastic materials. For Ti-6Al-4V in the flier plate and bumper shield we used Poisson's ratio $\nu=0.322$ and a yield stress $Y=12 \mathrm{kbar}$; for the $6061-\mathrm{T} 6$ aluminum backwall we assumed Poisson's ratio $\nu=0.33$ and a yield stress $Y=5 \mathrm{kbar}$. The ANEOS parameters used in the basecase CTH analyses are given in Table 3.1 [20].

These impact calculations were run in two stages, as described below. Input listings used for the two stages for the base case calculation are given in the appendices, for reference.

\subsection{Bumper Impact}

First, the impact of the flier plate onto the bumper shield was simulated, using fine resolution. The $x$-direction (radial) mesh was started at $x=0$, the axis of symmetry in the cylindrical coordinates used, while the $y$-direction (axial) mesh was started at $y=-0.5 \mathrm{~cm}$ with the initial contact surface between the flier plate and the bumper shield defined to be $y=0$. A subgrid of $400 \times 7500.01 \mathrm{~cm}$-square cells was used in an initial interaction region $8 \mathrm{~cm}$ in diameter and $7.5 \mathrm{~cm}$ in length (with additional cells growing at a $5 \%$ rate used outside this subgrid both axially and radially).

\subsection{Backwall Impact}

The initial impact calculation was run until the debris cloud had expanded to fill nearly the entire $400 \times 750$ square-cell subgrid which, for impacts of $\sim 10 \mathrm{~km} / \mathrm{s}$, took $\sim 6 \mu \mathrm{s}$. The material distribution at that time was then rezoned into a larger, coarser mesh which included the backwall. As in the first part of the calculation, the $x$-direction (radial) mesh was started at $x=0$, the axis of symmetry in the cylindrical coordinates used, and the $y$-direction (axial) mesh was started at $y=-0.5 \mathrm{~cm}$ with the initial contact surface between the flier plate and the bumper shield defined to be $y=0$. However, this mesh used a subgrid of $100 \times 4740.04 \mathrm{~cm}$-square, larger, cells to model a larger, later interaction region $8 \mathrm{~cm}$ in diameter but $19 \mathrm{~cm}$ in length (again with additional cells growing at a $5 \%$ rate used to model further regions). This second part of the calculation was run until backwall bulging and/or rupture was predicted and the backwall motion stopped. 
Table 3.1. ANEOS Equation-of-State Parameters Used in CTH Base Case Calculation

\begin{tabular}{|c|c|c|}
\hline $\begin{array}{l}\text { ANEOS } \\
\text { Parameter }\end{array}$ & $\begin{array}{c}\text { Flier/Bumper } \\
(\mathrm{Ti}-6 \mathrm{Al}-4 \mathrm{~V})\end{array}$ & $\begin{array}{c}\text { Backwall } \\
\text { (6061-T6 Aluminum) }\end{array}$ \\
\hline V1 & 3. & 1. \\
\hline V2 & 4. & 4. \\
\hline $\mathrm{V} 3$ & 4.42 & 2.7 \\
\hline V4 & 0.0 & 0.0 \\
\hline V5 & 0.0 & 0.0 \\
\hline V6 & $-4.99 \mathrm{e} 5$ & $7.63 \mathrm{e} 11$ \\
\hline V7 & 1.09 & 2.06 \\
\hline V8 & 0.036 & 0.0343 \\
\hline V9 & 0.80 & -1.0 \\
\hline V10 & 2. & 2. \\
\hline V11 & $9.766 \mathrm{e} 10$ & $1.2 \mathrm{e} 11$ \\
\hline V12 & 0.1654 & $-6.639 \mathrm{e} 9$ \\
\hline V13 & 0.0 & $3.5 \mathrm{e} 12$ \\
\hline V14 & 0.0 & 0.8 \\
\hline V15 & 0.0 & $2.7 \mathrm{e} 11$ \\
\hline V16 & 0.0 & 0.043 \\
\hline V17 & 3.54671 & 0.0 \\
\hline V18 & 0.0 & 0.0 \\
\hline V19 & 0.0 & 0.0 \\
\hline V20 & 0.0 & 0.0 \\
\hline V21 & 0.0 & 0.0 \\
\hline V22 & 0.0 & 0.0 \\
\hline V23 & $3.225 \mathrm{e} 9$ & $3.98 \mathrm{e} 9$ \\
\hline V24 & 0.95 & 0.924 \\
\hline $\mathrm{Z}(1)$ & 22. & 13. \\
\hline$F(1)$ & 0.9 & 1. \\
\hline$Z(2)$ & 13. & \\
\hline $\mathrm{F}(2)$ & 0.06 & \\
\hline $\mathrm{Z}(3)$ & 23. & \\
\hline$F(3)$ & 0.04 & \\
\hline
\end{tabular}




\section{Basecase Results}

Figure 4.1 shows the expansion of the debris cloud predicted at 1,2,3 and $4 \mu$ s after impact of the flier plate with the bumper at $9.66 \mathrm{~km} / \mathrm{s}$. The debris cloud configurations predicted at 5 and $6 \mu$ s are presented in Figures 4.2 and 4.3 , respectively. In these and subsequent debris cloud plots, contour lines show order-of-magnitude density variations, and dots highlight the higher-density core of the debris cloud. A high-density column, about equal in width to the original flier-plate diameter and travelling axially at about the original impact velocity, is visible in the debris cloud centerline; low-density material is seen expanding at higher velocity both laterally and axially from that central column. The material-interface lines indicate that the front half of the debris cloud consists of bumper-shield material, while the back half of the debris cloud consists of flier-plate material. The temperatures are highest in the center, with the column of higher-density material generally above the vaporization temperature, and most of the outer, low-density, material above the melt temperature.

Photographs from the XH-9 experiment (Figure 2.2) at $\sim 5.8 \mu$ s show the leading edge of the debris cloud travelling at $\geq 11 \mathrm{~km} / \mathrm{s}$ while radiographs at the same time give a velocity of $\sim 10 \mathrm{~km} / \mathrm{s}$; this indicates that the low-density vaporized debris front is travelling faster than the relatively higher density cloud imaged using X-rays. Based upon the debris cloud shown in Figure 4.3, CTH predicts the leading edge of the debris cloud $\left(\rho \geq 10^{-6} \mathrm{gm} / \mathrm{cm}^{3}\right)$ to be travelling at $\sim 12 \mathrm{~km} / \mathrm{s}$ and the higher-density inner core $\left(\rho \geq 10^{-1} \mathrm{gm} / \mathrm{cm}^{3}\right)$ to be travelling at $\leq 11 \mathrm{~km} / \mathrm{s}$, and are therefore qualitatively in reasonable agreement with test data.

The subsequent expansion of the debris cloud and its impact on the aluminum backwall structure is illustrated in Figure 4.4, at 10,15,20 and $25 \mu$ s after impact of the flier plate with the titanium-alloy bumper at $9.66 \mathrm{~km} / \mathrm{s}$. The resulting hole in the backwall structure, at the end of the calculation at $35 \mu \mathrm{s}$, is depicted in Figure 4.5; the predicted hole is unchanged between 30 and $35 \mu \mathrm{s}$, indicating that it has stopped growing. (In these and subsequent backwall structure plots, only material interface lines and dot densities are used, to avoid visual clutter and highlight the condition of the back wall.) As expected, the rupture occurs on the centerline where the higher-density central column of debris impacts.

Figures 4.6 and 4.7 present pressure histories, and associated impulse delivered, for a number of history points embedded in the backwall structure at various distances radially outward from the impact centerline. The impact of the debris cloud causes a pressure rise, first visible on the centerline at $\sim 12.5 \mu$ s and beginning later further out on the backwall. The pressure peaks at $\sim 15 \mu$ s while there is yet no motion of the backwall (as seen in the upper right plot in Figure 4.4), and then falls as the back wall responds by bulging outward (as seen in the lower left plot in Figure 4.4). Both the pressures and the associated impulse drop off continuously with increasing distance from the centerline, where lower-density debris cloud material impacts the back wall. 


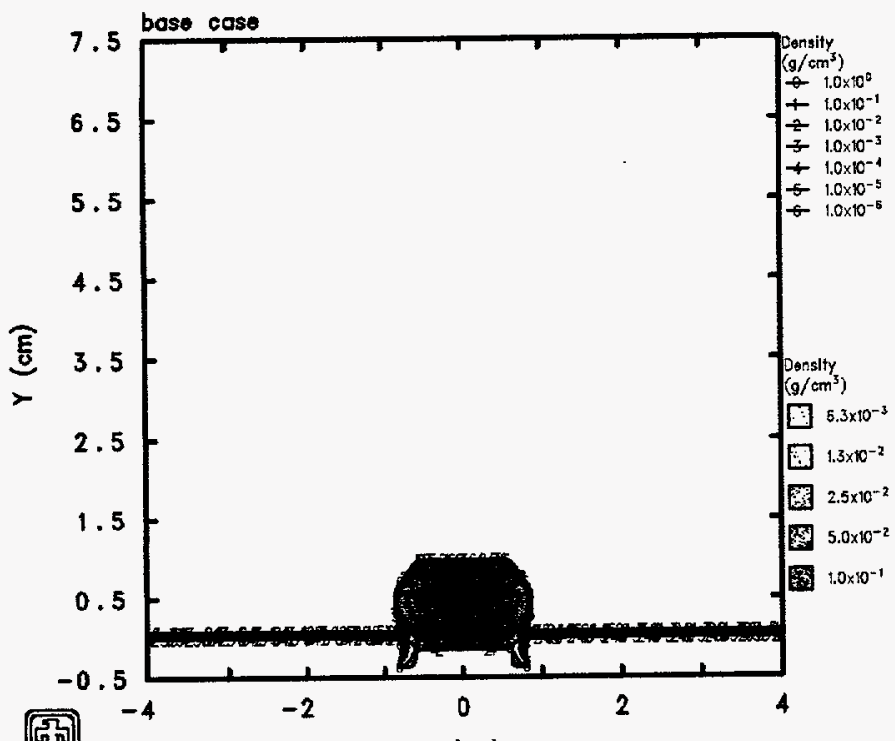

[5] $20 \mathrm{C}$ Back 1

(Tim EOS) 2 de cth XN9 $\mathrm{mm}$ TIAN plate $9.66 \mathrm{~km} / \mathrm{s}$ on $29 \mathrm{mil}-$ TIAlV J20CFC 10/29/92 14:34:19 CTH 286 Time $=1.0014 \times 10^{-6}$

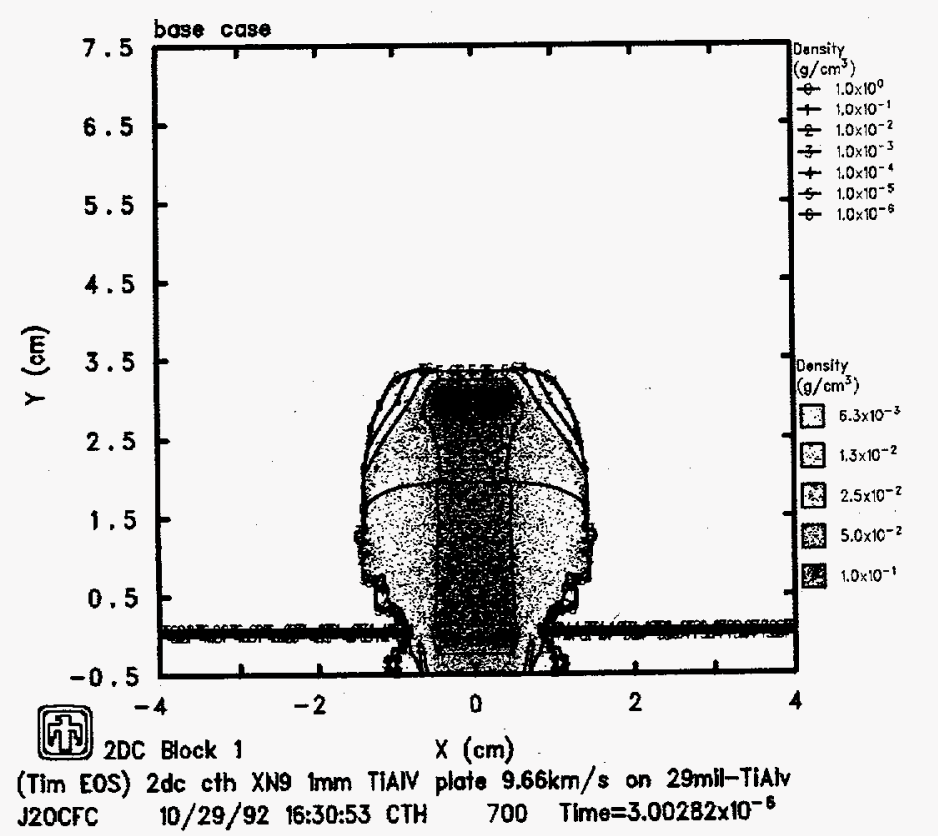

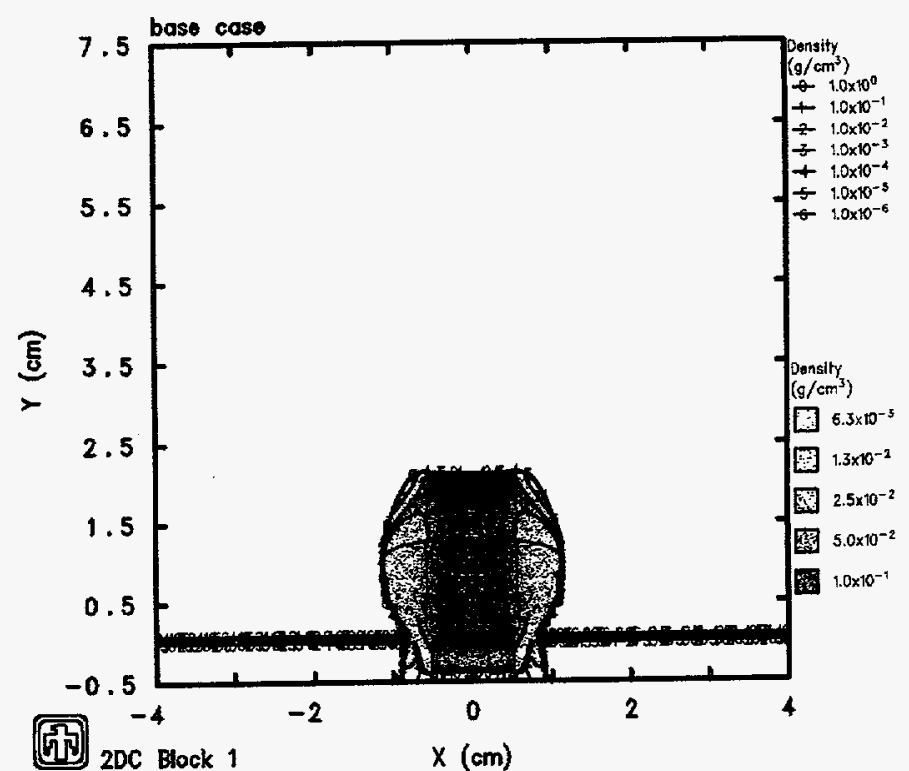

(T/m EOS) 2 de cth XN9 $\mathrm{tmm}$ TIAIV plate $9.66 \mathrm{~km} / \mathrm{s}$ on $29 \mathrm{mil}-$ TIAlv J20CFC 10/29/92 15:12:14 CTH 486 Time $=2.0038 \times 10^{-8}$

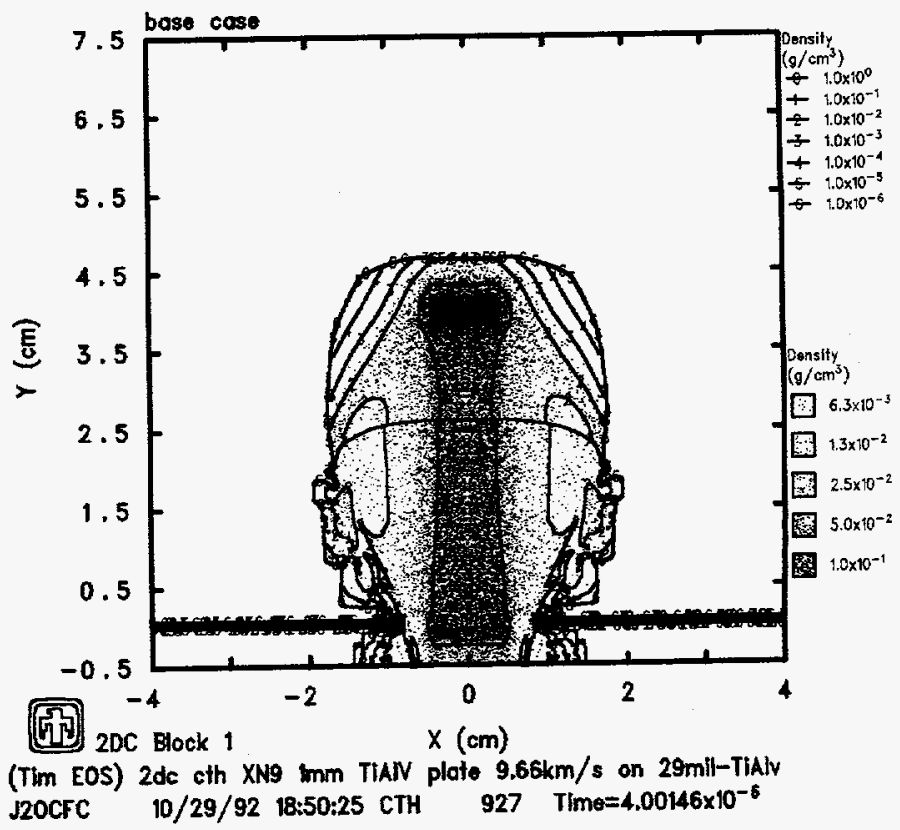

Figure 4.1. Debris Cloud at $1 \mu \mathrm{s}$ (upper left), $2 \mu \mathrm{s}$ (upper right), $3 \mu \mathrm{s}$ (lower left), and $4 \mu \mathrm{s}$ (lower right) for Base Case Calculation 


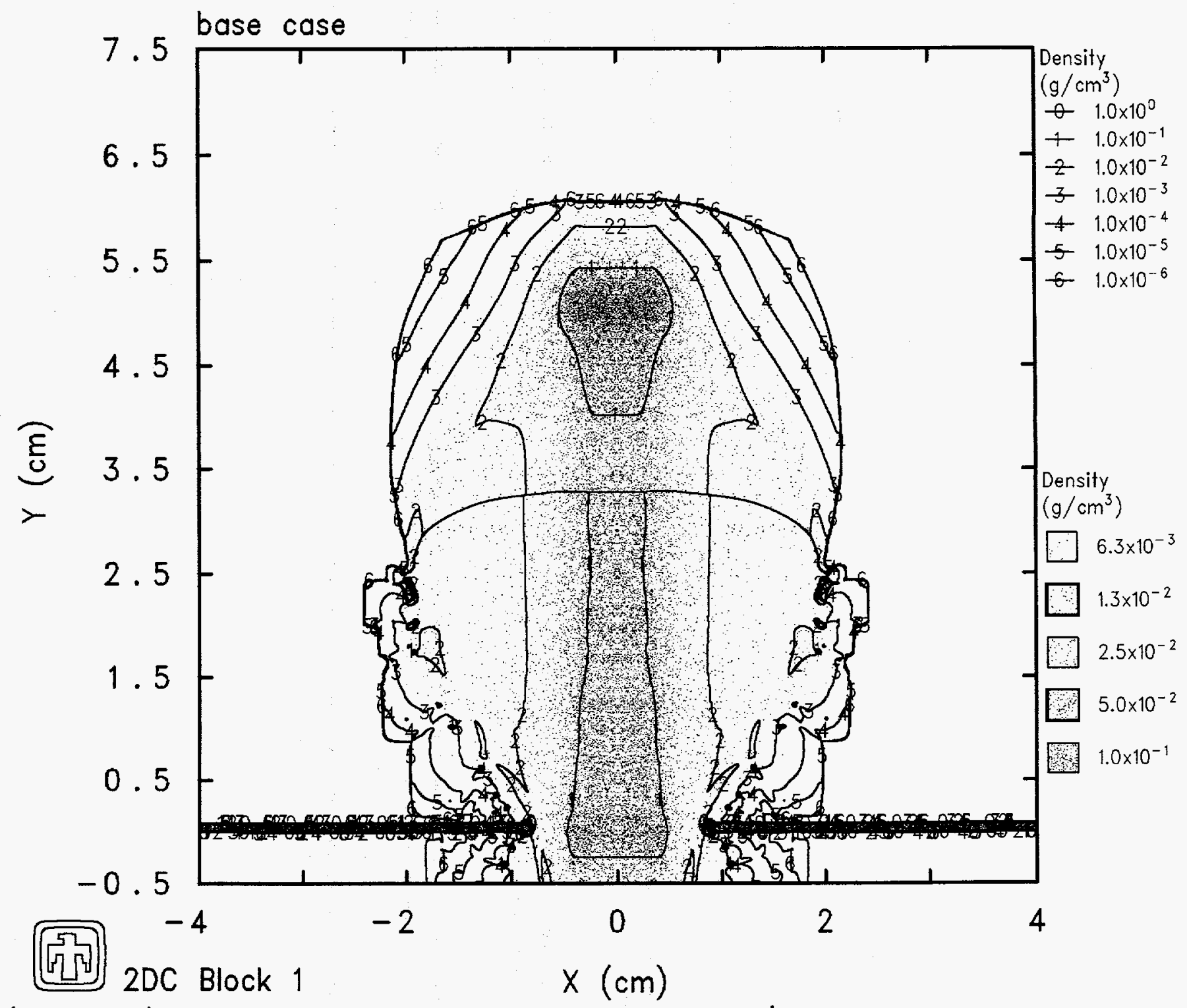

(Tim EOS) $2 \mathrm{dc}$ cth XN9 $1 \mathrm{~mm}$ TiAlV plate $9.66 \mathrm{~km} / \mathrm{s}$ on $29 \mathrm{mil}-$ TiAlv J2OCFC $\quad 10 / 29 / 92 \quad 22: 48: 25 \mathrm{CTH} \quad 1165$ Time $=5.00038 \times 10^{-6}$

Figure 4.2. Debris Cloud at $5 \mu$ s for Base Case Calculation 


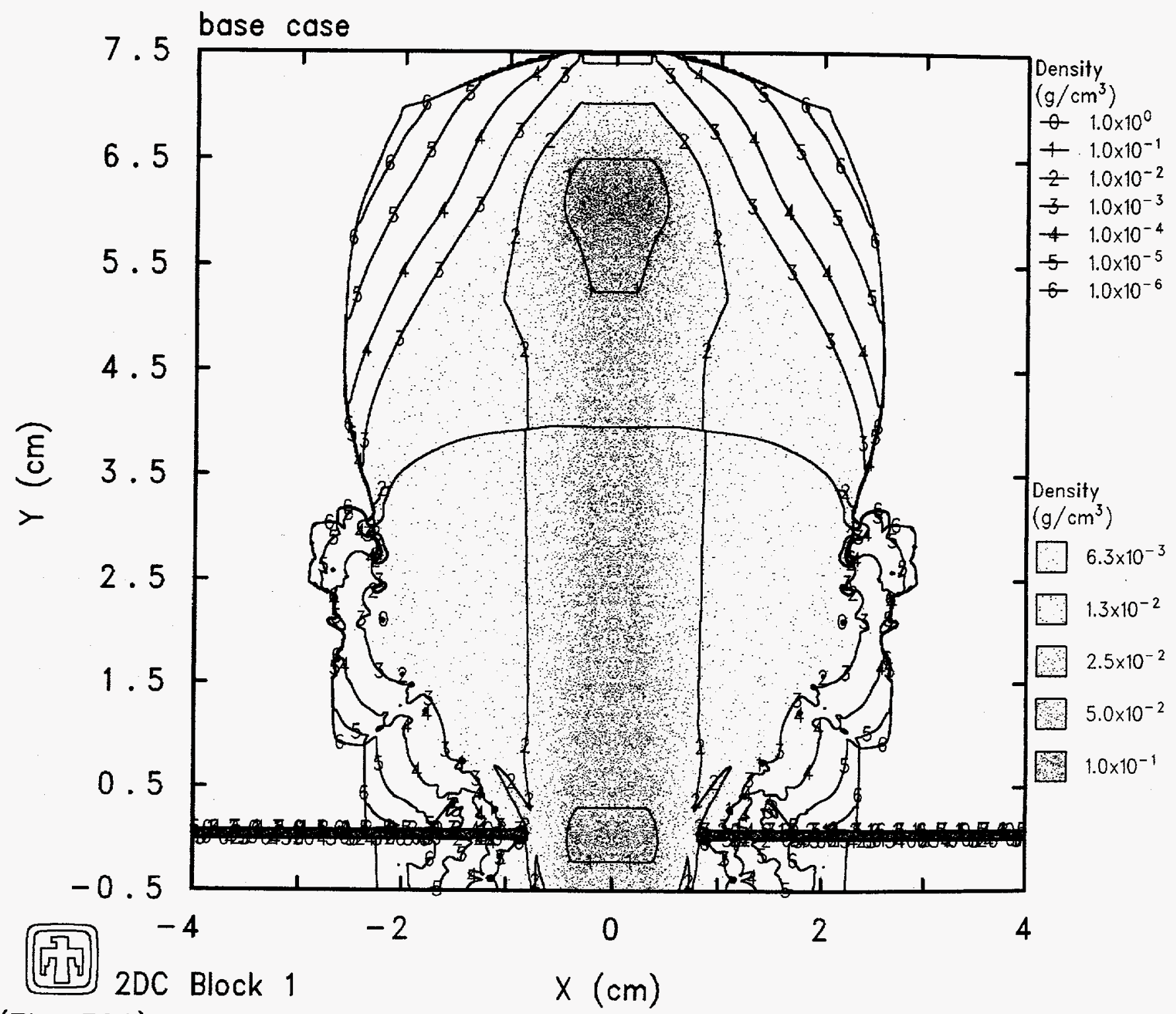

(Tim EOS) $2 \mathrm{dc}$ cth XN9 $1 \mathrm{~mm}$ TiAlV plate $9.66 \mathrm{~km} / \mathrm{s}$ on $29 \mathrm{mil}-$ TiAlv KBNCOR $\quad 11 / 02 / 9215: 28: 59 \mathrm{CTH} \quad 1408 \quad$ Time $=6.00204 \times 10^{-6}$

Figure 4.3. Debris Cloud at $6 \mu$ s for Base Case Calculation 


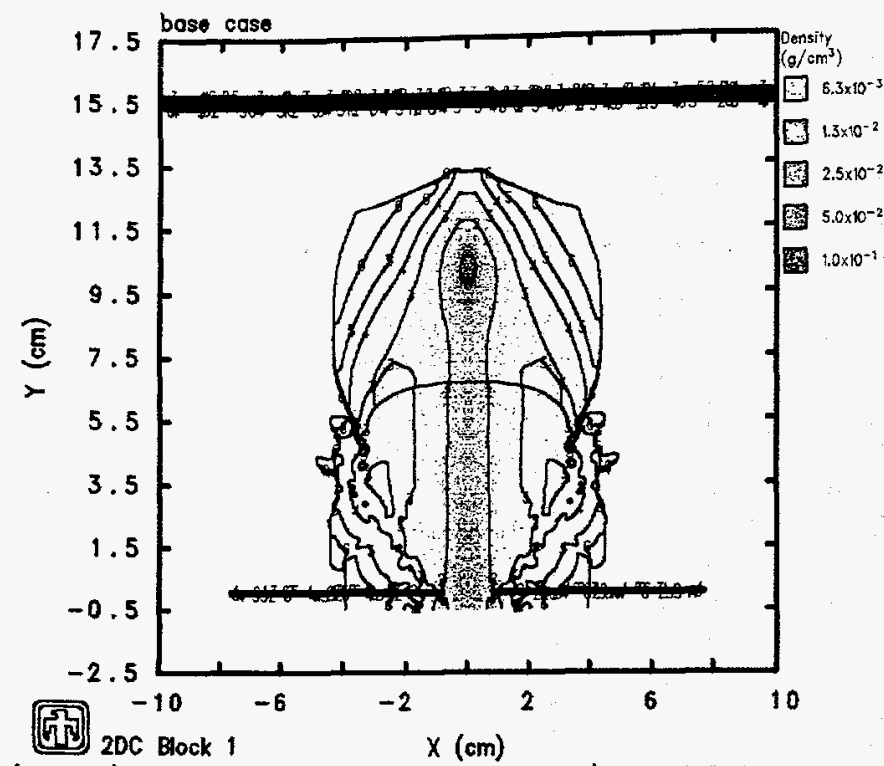

(TIM EOS) 2DC CTH XN9 MM TIALV PLATE $9.66 \mathrm{KM} / \mathrm{S}$ ON 29MIL-TIALV KCKAUW 11/03/92 11:07:24 CTH 297 TIme=1.0011 $\times 10^{-3}$

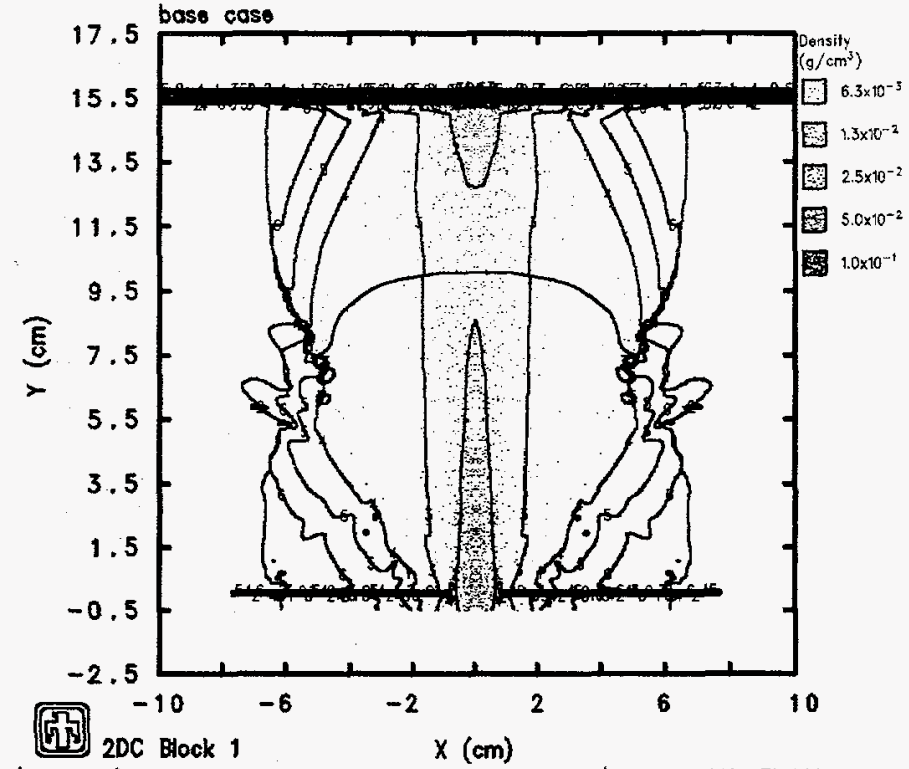

(TM EOS) 2DC CTH XNG MM TIALV PLATE $9.66 \mathrm{KM} / \mathrm{S}$ ON 29LIL-TIALV KCKAUW $\quad 11 / 03 / 92 \quad 7: 47: 20 \mathrm{CTH} \quad 1176$ Time $=1.5002 \times 10^{-5}$

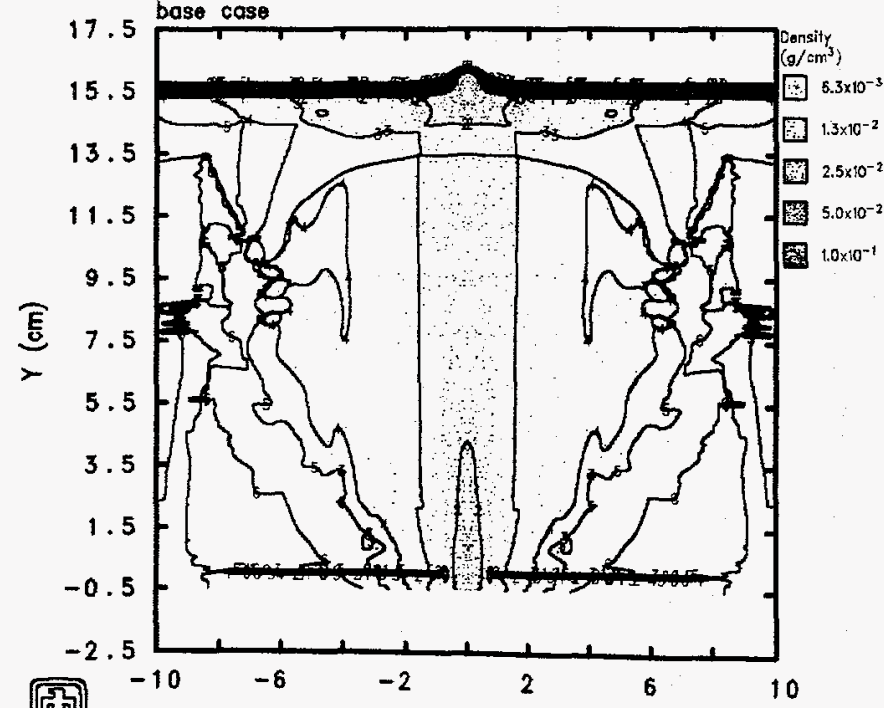

[1개 $2 D C$ Block 1

(TIM EOS) $20 \mathrm{C}$ CTH XNG IMM TIALV PLATE $9.66 \mathrm{KM} / \mathrm{S}$ ON 29MIL-TIALV KCKAUW $11 / 04 / 92 \quad 06: 02: 28 \mathrm{CTH} 2554$ Tíme $=2.00013 \times 10^{-5}$

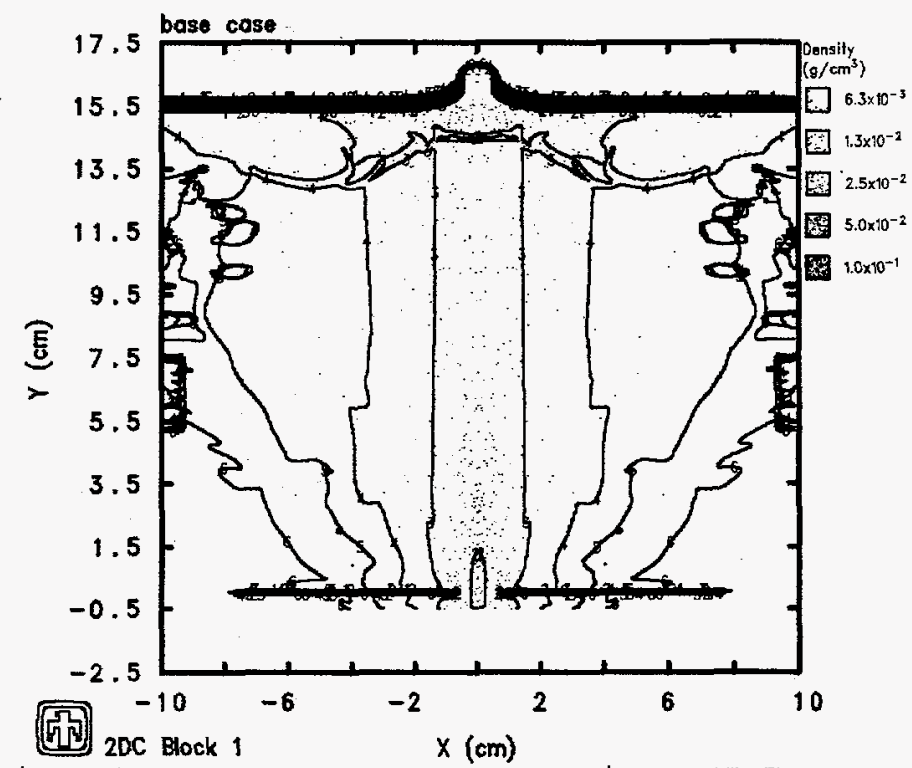

(TMM EOS) $20 \mathrm{C}$ CTH XN9 1MM TIALV PLATE 9.66KM/S ON 29ML-TIALV KDNBFO $11 / 04 / 92 \quad 2 \mathrm{t}: 27: 11 \mathrm{CTH} 3723$ TIme $=2.50086 \times 10^{-5}$

Figure 4.4. Debris Cloud and Backwall Structure at $10 \mu \mathrm{s}$ (upper left), $15 \mu \mathrm{s}$ (upper right), $20 \mu \mathrm{s}$ (lower left), and $25 \mu \mathrm{s}$ (lower right) for Base Case Calculation 


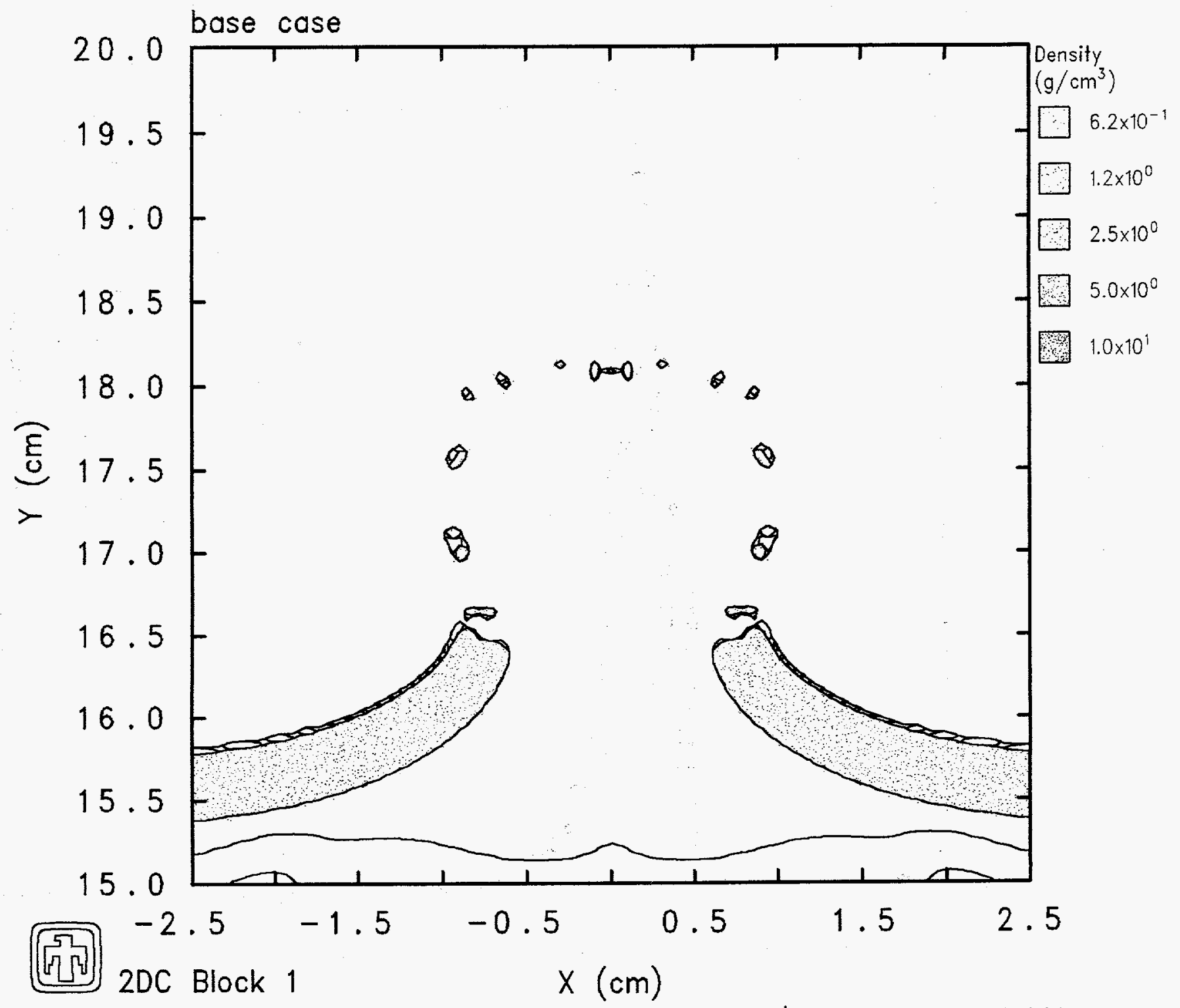

(TIM EOS) 2DC CTH XN9 1MM TIALV PLATE 9.66KM/S ON 29ML-TIALV KIOCLL $\quad 11 / 10 / 92 \quad 01: 02: 23 \mathrm{CTH} \quad 4726 \quad$ Time $=3.50076 \times 10^{-5}$

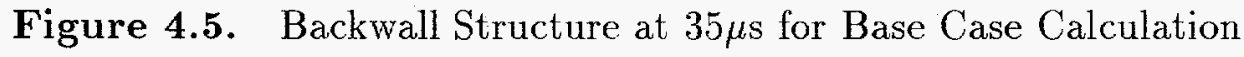




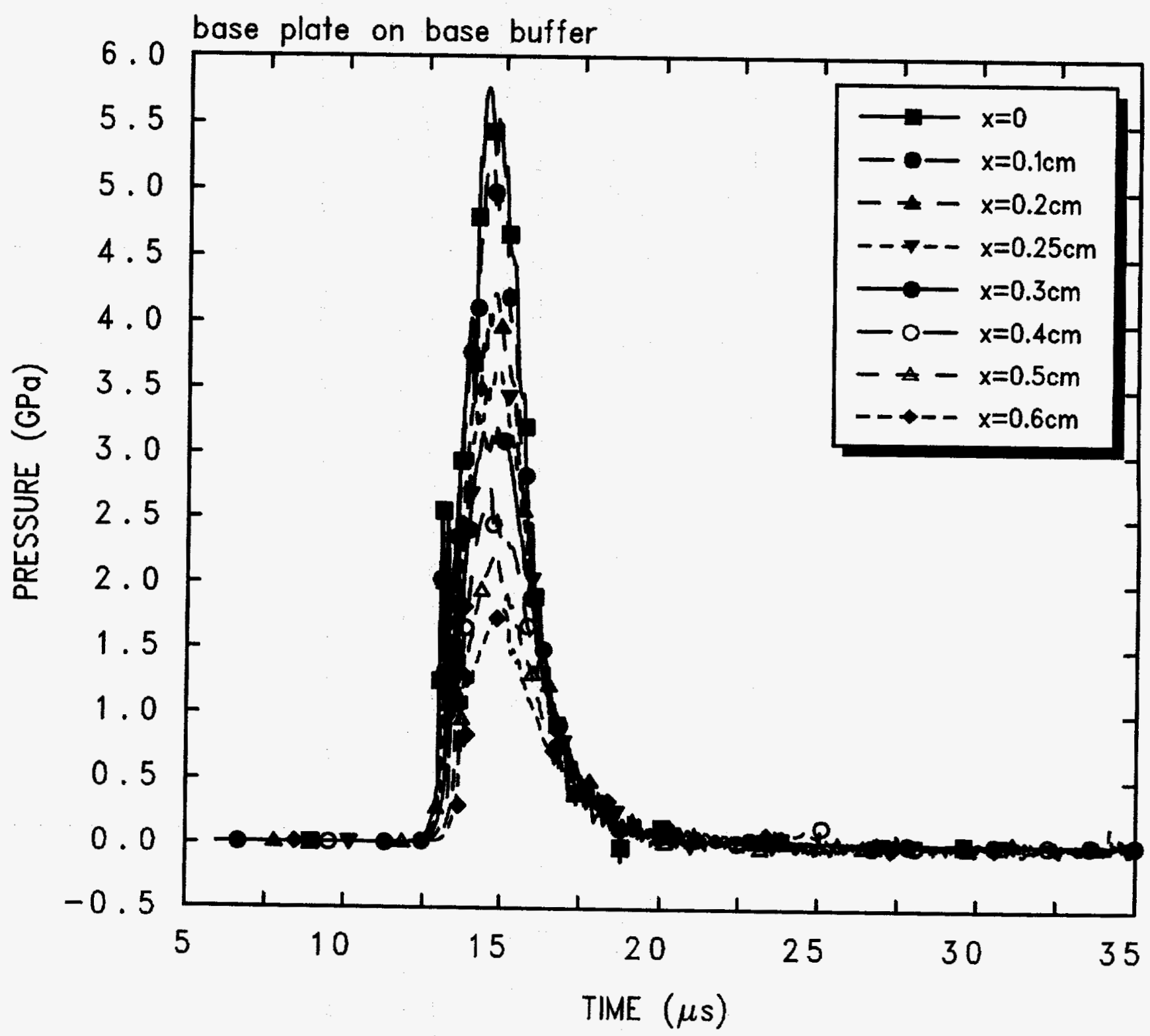

Figure 4.6. Pressure on Backwall for Base Case Calculation 


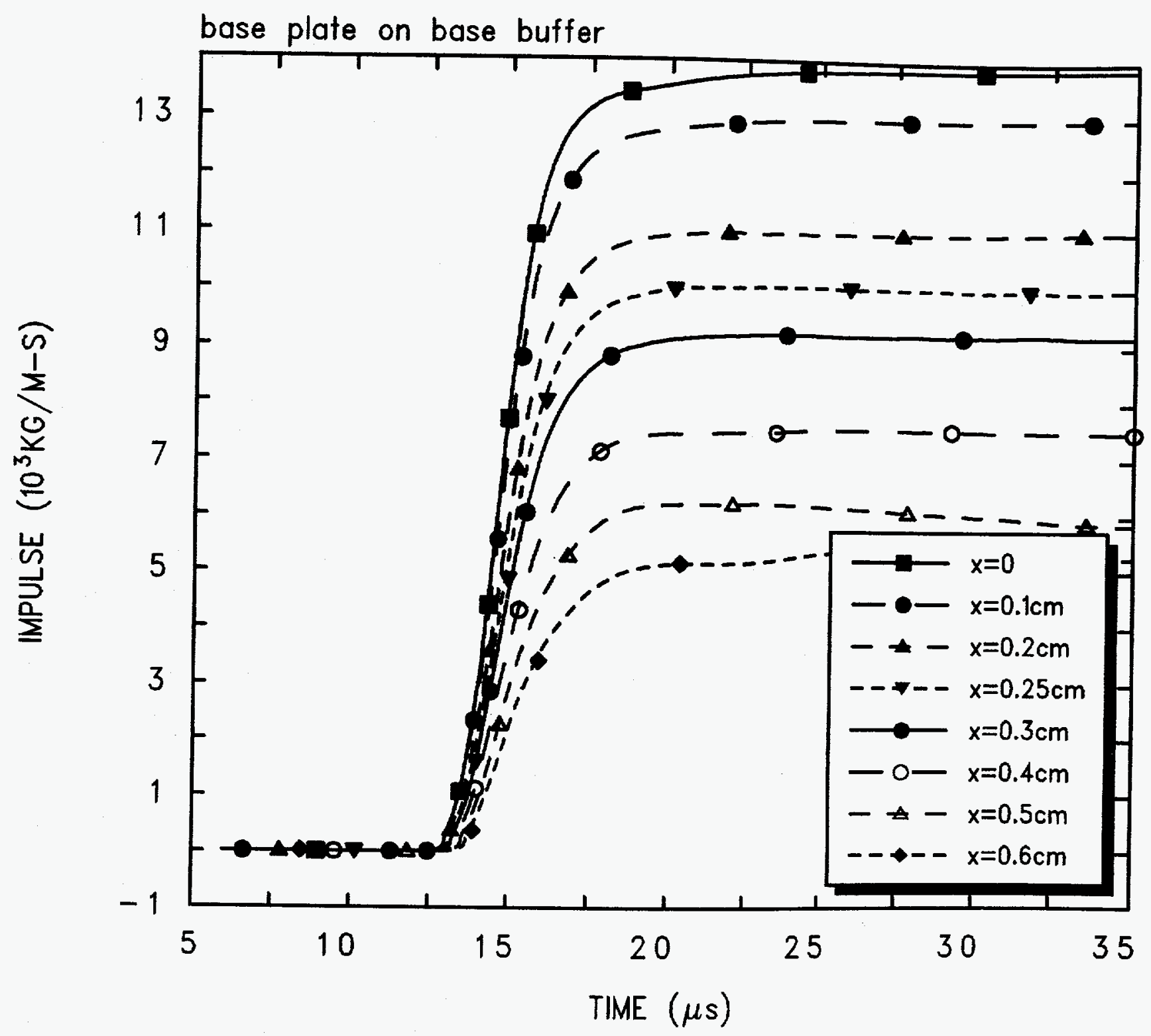

Figure 4.7. Impulse on Backwall for Base Case Calculation 


\section{$5 \quad$ Variational Studies}

In Section 4, CTH simulations of tests performed to evaluate the integrity of a titanium-alloy Whipple bumper shield located at $152 \mathrm{~mm}$ from the space structure at impact velocities of $\sim 10 \mathrm{~km} / \mathrm{s}$ were presented; that study helps determine the "mass" requirements of the orbital debris for the integrity of a backwall structure, and the reliability of using hydrocode simulations to represent these classes of investigations. The generally good agreement between calculations and experiments has allowed us to perform computational "gedanken" studies. This has resulted in an evaluation of the effect of increased vapor concentration in a debris cloud for a fixed mass of the orbital debris to protect a backwall structure, as a possible approach to a mitigating strategy. The results of this study are summarized in this section.

Three different variations were done on the problem described above in Section 4, to increase the vapor concentrations in the debris cloud.

- In the first study, the materials, dimensions and impact velocity were left unchanged, while the initial temperatures of the flier plate and/or bumper shield were varied as shown in Table 5.1 (to increase the vapor content in the the debris cloud); note that the melting temperature of $\mathrm{Ti}-6 \mathrm{Al}-4 \mathrm{~V}$ is $1943 \mathrm{~K}$ and the vaporization temperature is $3533 \mathrm{~K}$.

- In the second study, the materials, dimensions and initial temperatures were unchanged, but the impact velocity was progressively increased to $\sim 20$ and $\sim 30 \mathrm{~km} / \mathrm{s}$.

- In the third study, the flier material, dimensions and the impact velocity were unchanged but the bumper shield material was changed to plexiglass and to cadmium. These materials were selected as lower- and higher-density materials than Ti-6Al-4V but with similar, low melt points. The thickness of the bumper shield was adjusted to maintain constant areal densities, as indicated in Table 5.2.

(The backwall was identical in all cases.)

\subsection{Initial Temperature Variations}

The debris cloud propagation seen in the first set of calculations (increasing the initial temperature of the flier plate and/or bumper shield) differs due to the varying amounts of molten and vaporized material produced in the initial impact. Figure 5.1.1 shows the debris cloud extent predicted by $\mathrm{CTH}$ at $5 \mu$ s after initial impact of the flier plate with the bumper shield, for the base case problem and for the three sensitivity studies identified in Table 5.1. Contours showing order-of-magnitude changes in the density and dot densities are included to highlight the debris cloud internal structure.

At $5 \mu$ s after impact, the flier-plate debris consists of about equal amounts of molten and vaporized material in the base case analysis; in the "hot-bumper" and "hot" calculations, in contrast, the flier plate debris is between $50 \%$ and $60 \%$ vaporized at this 
Table 5.1. Initial-Temperature Variation Study Input

$\begin{array}{lcc}\text { Case ID } & \text { Flier Temperature } & \text { Bumper Temperature } \\ \text { Base Case } & 300 \mathrm{~K} & 300 \mathrm{~K} \\ \text { "Hot Bumper" } & 300 \mathrm{~K} & 1923 \mathrm{~K} \dagger \\ \text { "Hot" } & 1923 \mathrm{~K} \dagger & 1923 \mathrm{~K} \dagger \\ \text { "Very Hot" } & 3513 \mathrm{~K} \ddagger & 3513 \mathrm{~K} \ddagger \\ & & \\ & \dagger 1923 \mathrm{~K}=\mathrm{T}_{\text {MELT }}-20 \mathrm{~K} \\ & \ddagger 3513 \mathrm{~K}=\mathrm{T}_{V A P}-20 \mathrm{~K}\end{array}$

Table 5.2. Bumper-Material Variation Study Input

\begin{tabular}{lcccc} 
Bumper Material & $\begin{array}{c}\text { Density } \\
\left(\mathrm{gm} / \mathrm{cm}^{3}\right)\end{array}$ & $\begin{array}{c}\text { Thickness } \\
(\mathrm{cm})\end{array}$ & $\begin{array}{c}\mathrm{T}_{\text {MELT }} \\
(\mathrm{K})\end{array}$ & $\begin{array}{c}\mathrm{T}_{V A P} \\
(\mathrm{~K})\end{array}$ \\
& & & & \\
Ti-6Al-4V (Base Case $)$ & 4.42 & 0.0762 & 1943 & 3533 \\
Cadmium & 8.92 & 0.0381 & 594 & 1040 \\
Plastic & 1.18 & 0.2667 & $300-400 \dagger$ \\
& \multicolumn{4}{c}{$\dagger$ decomposition }
\end{tabular}



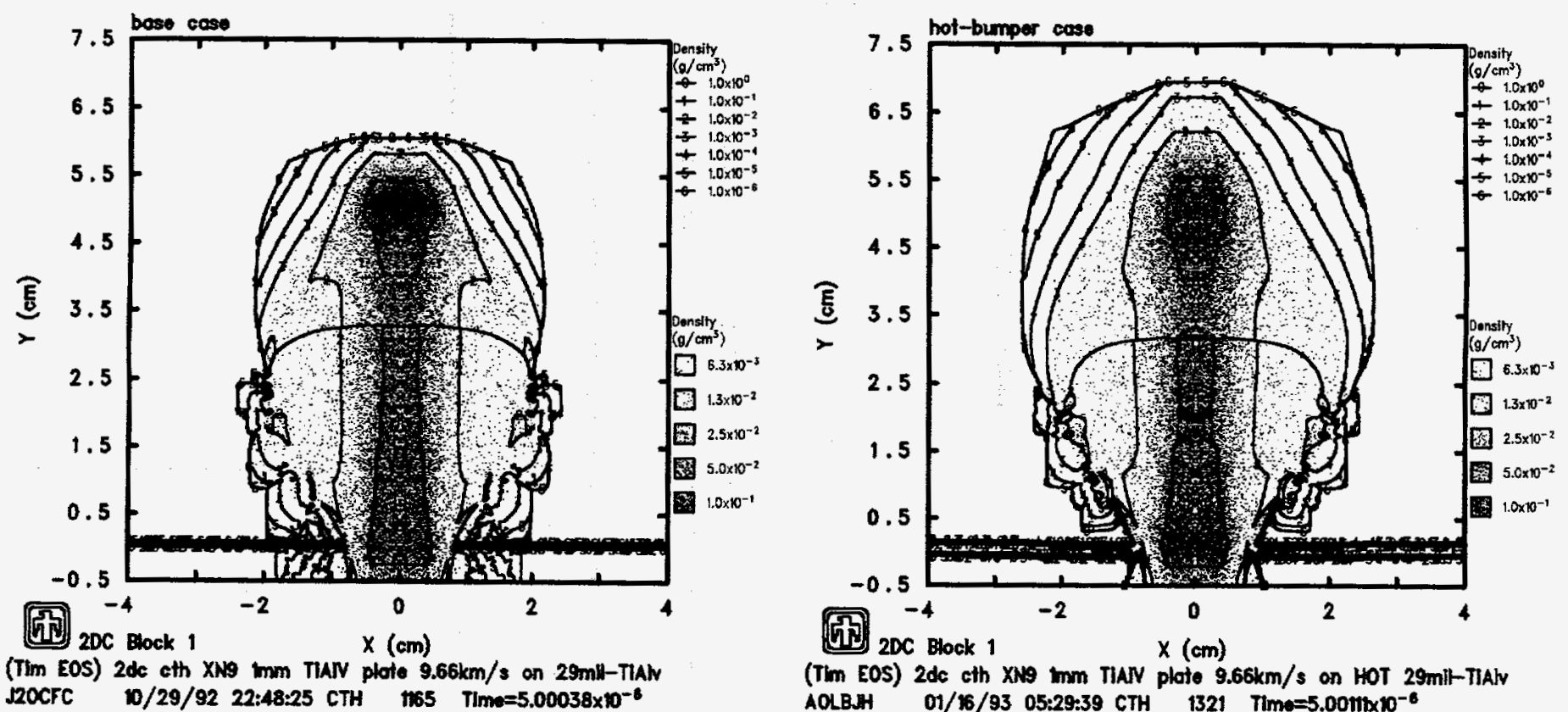

2DC Block 1

(Thm EOS) $2 \mathrm{dc}$ cth XN9 $\mathrm{mm}$ TIAN plote $9.66 \mathrm{~km} / \mathrm{s}$ on HOT $29 \mathrm{mil}-T I A H \mathrm{r}$ AOLBH $01 / \% 6 / 93$ 05:29:39 CTH 1321 Time $=5.0011 \times 10^{-6}$

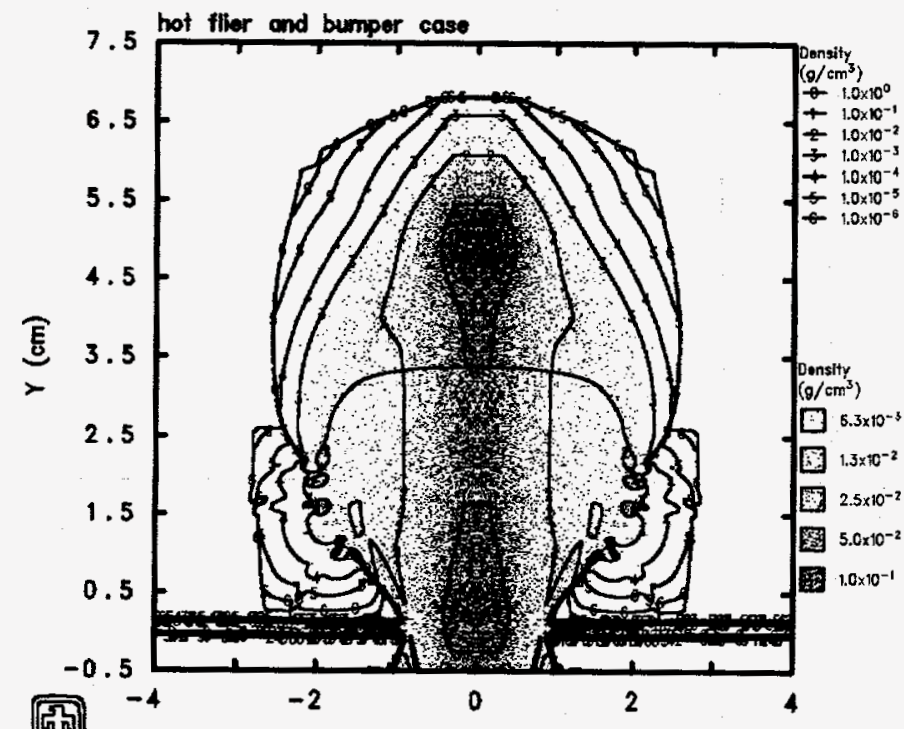

[1] $20 \mathrm{C}$ Block 1

$X(\mathrm{~cm})$

(TIm EOS) 2 de eth XN9 $\mathrm{mm}$ TIAIV HOT-plate $9.66 \mathrm{~km} / \mathrm{s}$ on HOT $29 \mathrm{mi}$-TIAlV IKOEAQ $2 / 12 / 92$ 05:52:58 CTH 1299 Time $=5.00105 \times 10^{-6}$

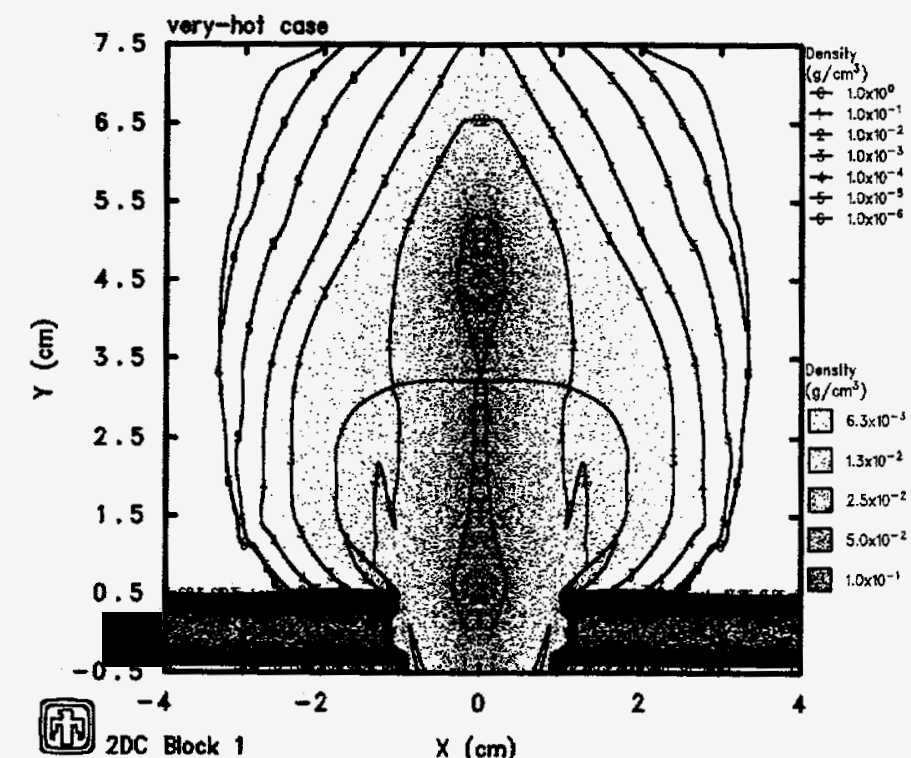

(Tim EOS) 2 de cth XNG $\mathrm{mm}$ TIAN VHOT-plote $9.66 \mathrm{~km} / \mathrm{s}$ on VHOT $29 \mathrm{mil}-T I A l v$ LUNAPR $12 / 22 / 9200: 34: 47 \mathrm{CTH} 1535$ Thme $=5.00258 \times 10^{-8}$

Figure 5.1.1. Debris Cloud at $5 \mu$ s for Base Case Calculation (upper left), "Hot-Bumper" (upper right), "Hot" (lower left) and "Very-Hot" (lower right) Initial Temperature Variations 
time and, in the "very-hot" calculation, the flier plate debris is about $67 \%$-vapor at this time, due to the higher initial temperatures. (Note that the fraction of material molten or vaporized is estimated simply based upon the amount of material above the melt or vaporization temperature.)

The debris cloud in the base case analysis travels the slowest and has dispersed the least, while the debris cloud in the "very-hot" case travels the fastest and has dispersed the most.

As a result, the pressures and associated impulse imparted to the backwall are distributed differently in each of these four cases (when compared to the base case), in both space and in time, as shown in Figures 5.1.2 and 5.1.3 for points in the back wall at various distances from the impact centerline. For all distances $\leq 0.5 \mathrm{~cm}$ from the impact, the impulse is significantly higher in the base case, and most of that impulse is accumulated in a relatively brief period (from $\sim 12.5 \mu$ s to $\sim 17.5 \mu \mathrm{s}$ ). In the "very-hot" calculation, due to the higher fraction of vaporized material, the impulse is significantly lower and is accumulating slowly. In the two intermediate cases, the final impulse in the region $\leq 0.25 \mathrm{~cm}$ from the impact centerline is $\sim 65-80 \%$ lower than in the base case, and is accumulated over a somewhat longer period (from $\sim 12.5 \mu \mathrm{s}$ to $\sim 22.5 \mu \mathrm{s}$ ).

The final configuration of the backwall in these four cases is shown in Figure 5.1.4. The greater, more localized and more rapid impulsive loading predicted by the base case results in late-time rupture of the backwall, while the lower and slower loadings predicted by the other three, elevated-temperature cases merely flex or bulge the backwall slightly. This suggests, therefore, that a "hot" bumper sheet has the potential of "stopping" a hypervelocity projectile, when compared to a "cold" bumper plate, but needs to be substantiated experimentally.

\subsection{Impact Velocity Variations}

An alternate way to generate more vaporized material in a debris cloud is to have the initial impact occur at higher velocities. Figure 5.2.1 shows the debris clouds resulting from a $\sim 20 \mathrm{~km} / \mathrm{s}$ impact at $2.5 \mu \mathrm{s}$ and from a $\sim 30 \mathrm{~km} / \mathrm{s}$ impact at $1.6 \mu \mathrm{s}$; these times correspond to the debris cloud location at $\sim 5 \mu$ s for the base case $\sim 10 \mathrm{~km} / \mathrm{s}$ impact (presented in Figure 4.2 ). The flier plate material in these debris clouds is $\sim 78 \%$ and $\sim 82 \%$ vapor at the $20 \mathrm{~km} / \mathrm{s}$ and $30 \mathrm{~km} / \mathrm{s}$ impact velocities, respectively, compared to $\sim 50 \%$ vapor in the basecase. However, since the leading edge of the vapor is travelling much faster in this case, it does not have sufficient time to disperse the debris as efficiently as in the initial-temperature variations discussed in Section 5.1. Therefore, a greater impulse is imparted to the backwall more rapidly for higher initial impact velocities, as illustrated in Figures 5.2.2 and 5.2.3 for a number of points in the backwall.

Thus, although the thermal state of debris clouds resulting from higher-velocity impacts may be such that more vapor is present, the debris cloud has sufficient concentrated kinetic energy to rupture the back wall. The diameter of the resulting hole was predicted to be $2.06 \mathrm{~cm}$ and $3.10 \mathrm{~cm}$, respectively, for initial impact velocities of $\sim 20 \mathrm{~km} / \mathrm{s}$ 

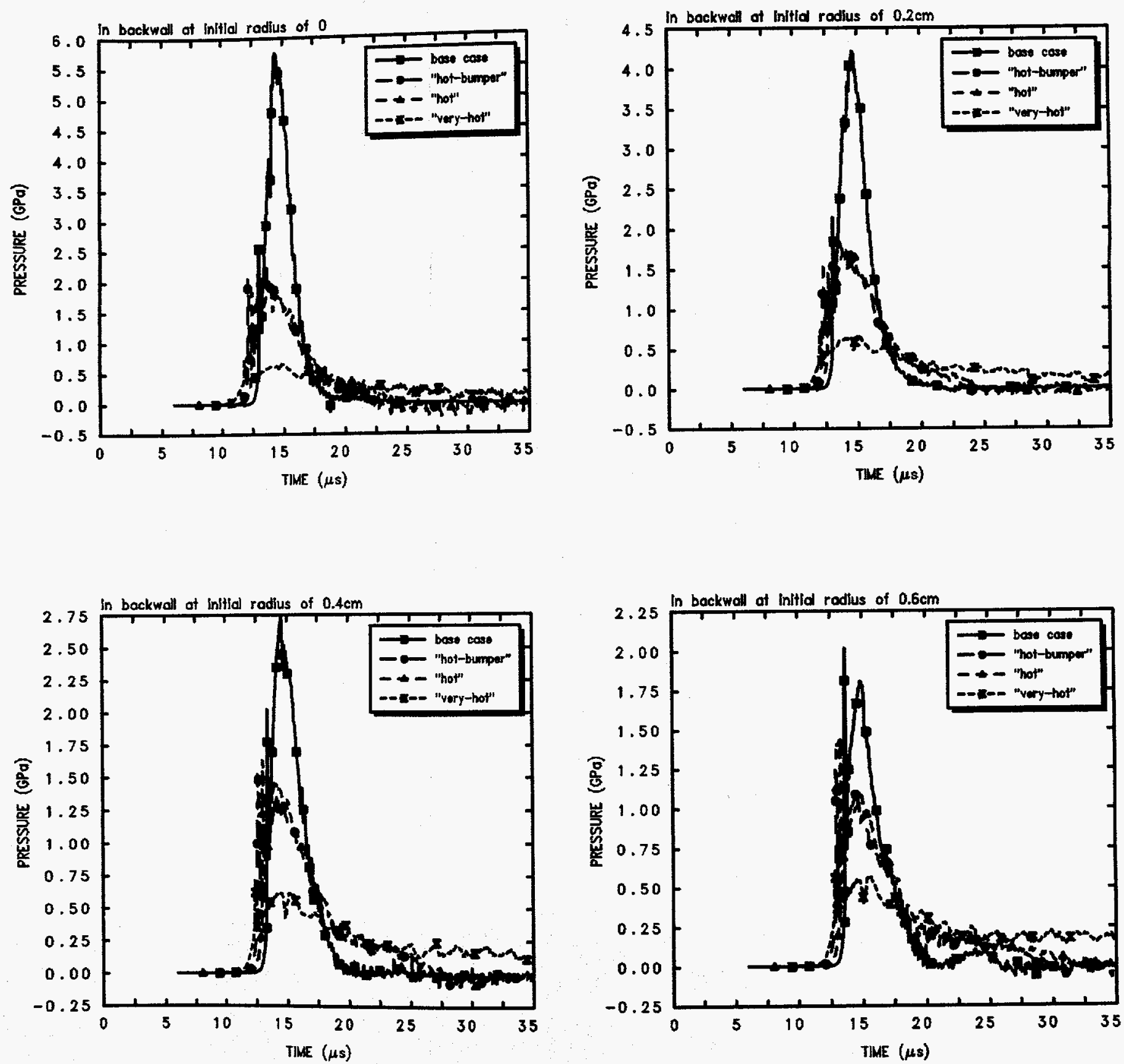

Figure 5.1.2. Pressure on Backwall at Radial Distance of 0 (upper left), $0.2 \mathrm{~cm}$ (upper right), $0.4 \mathrm{~cm}$ (lower left) and $0.6 \mathrm{~cm}$ (lower right) for Base Case Calculation and Initial Temperature Variations 

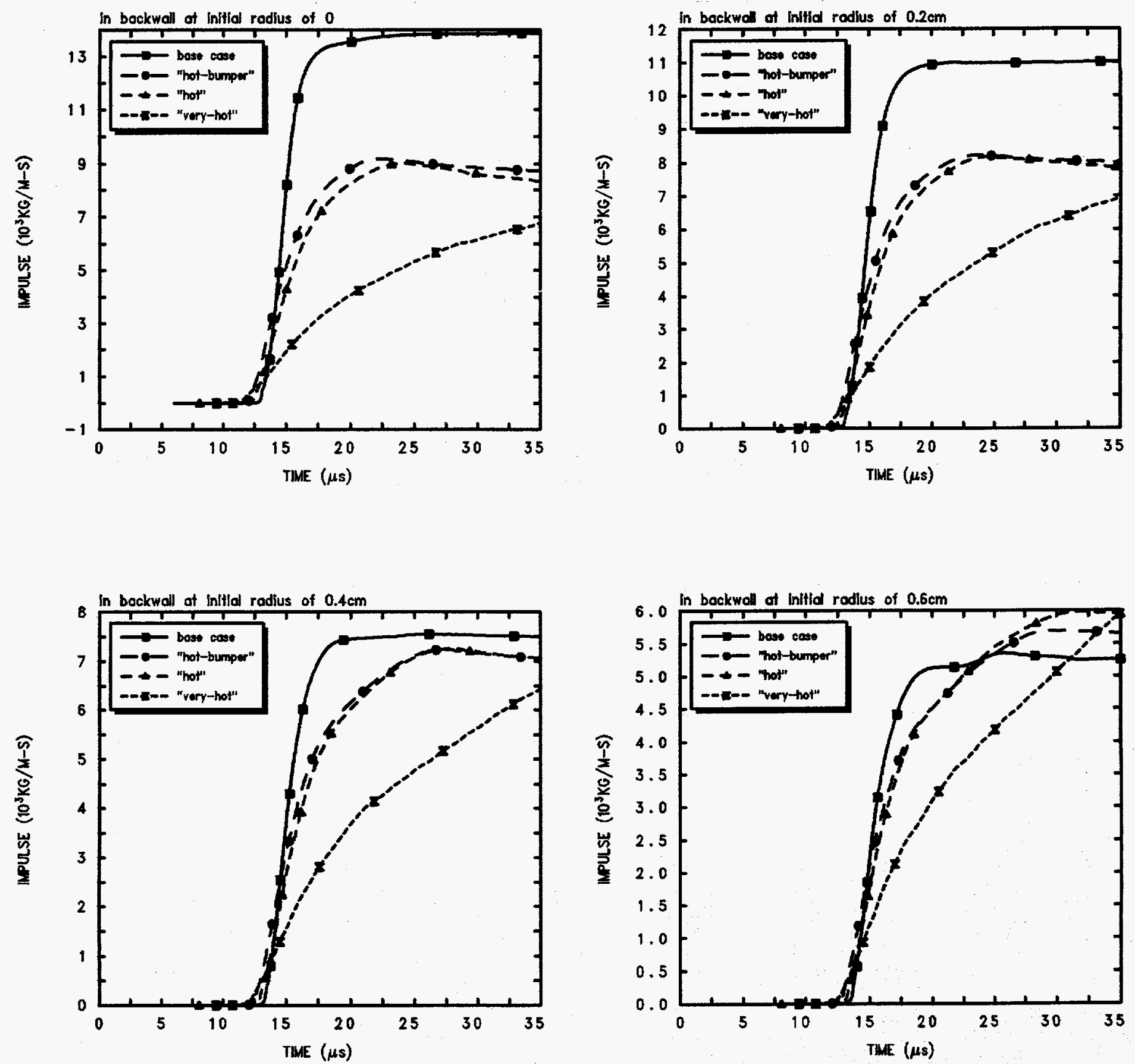

Figure 5.1.3. Impulse on Backwall at Radial Distance of 0 (upper left), $0.2 \mathrm{~cm}$ (upper right), $0.4 \mathrm{~cm}$ (lower left) and $0.6 \mathrm{~cm}$ (lower right) for Base Case Calculation and Initial Temperature Variations 


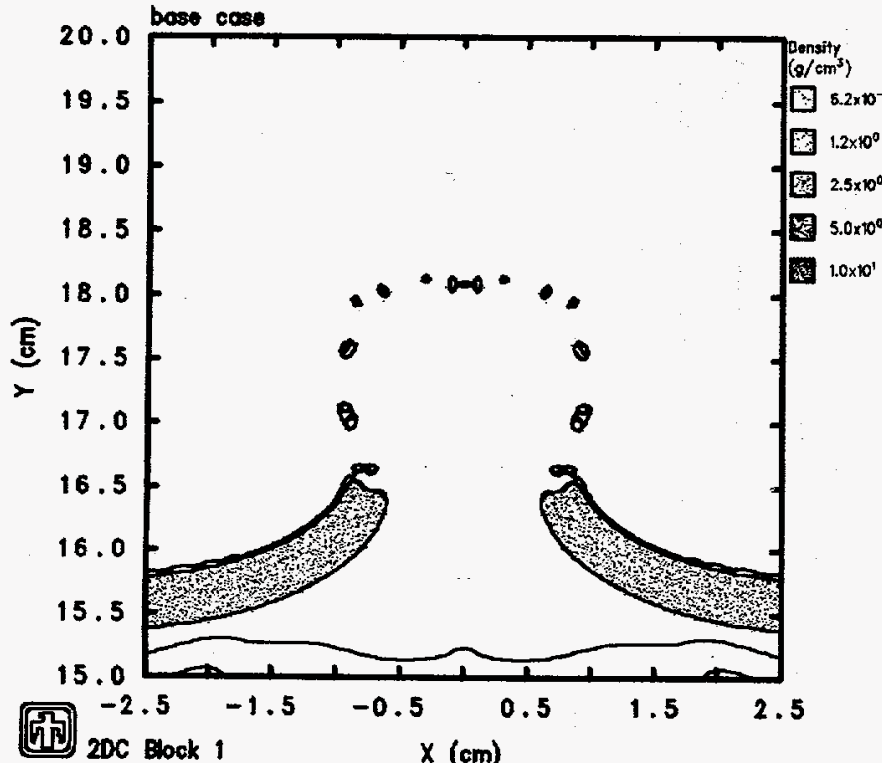

(TM EOS) $20 \mathrm{C}$ CTH XN9 MA THALV PLATE $9.66 \mathrm{KM} / \mathrm{s}$ ON 29M-TIALV KOCLL $11 / 10 / 92$ Ot:02:23 CTH 4726 Timo=3.50076 $\times 10^{-5}$

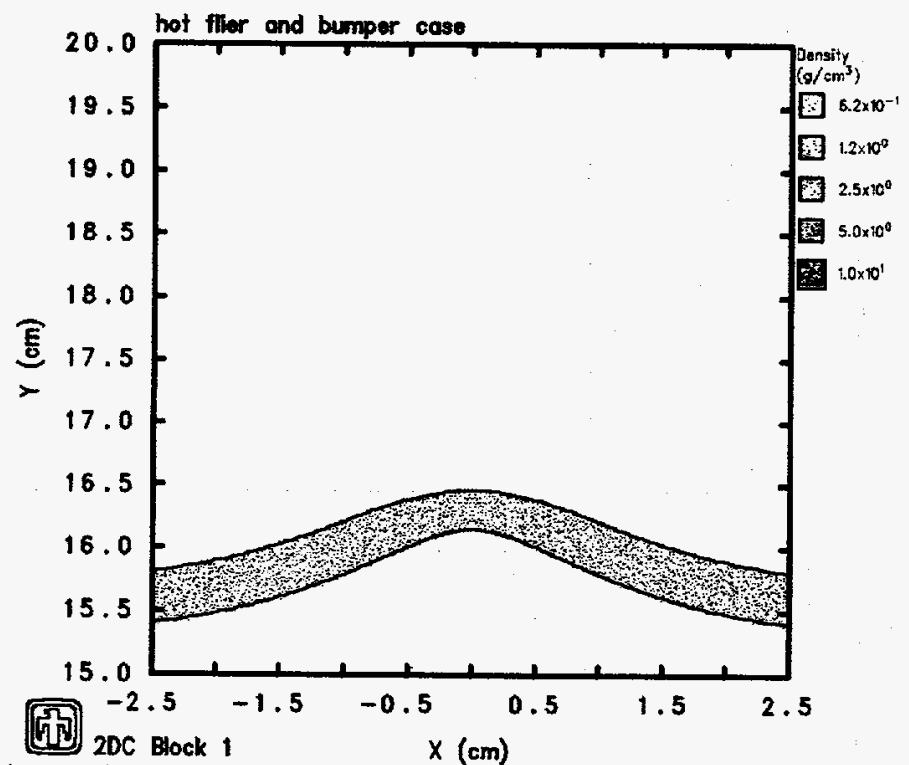

(TM EOS) 2DC CTH XN9 IMM HOT TIALV PLATE 9.66KM/S ON HOT 29MLLTIALV LNLABL $12 / 6 / 92 \quad 01: 19: 34$ CTH $4351 \quad T m e=3.50041 \times 10^{-5}$

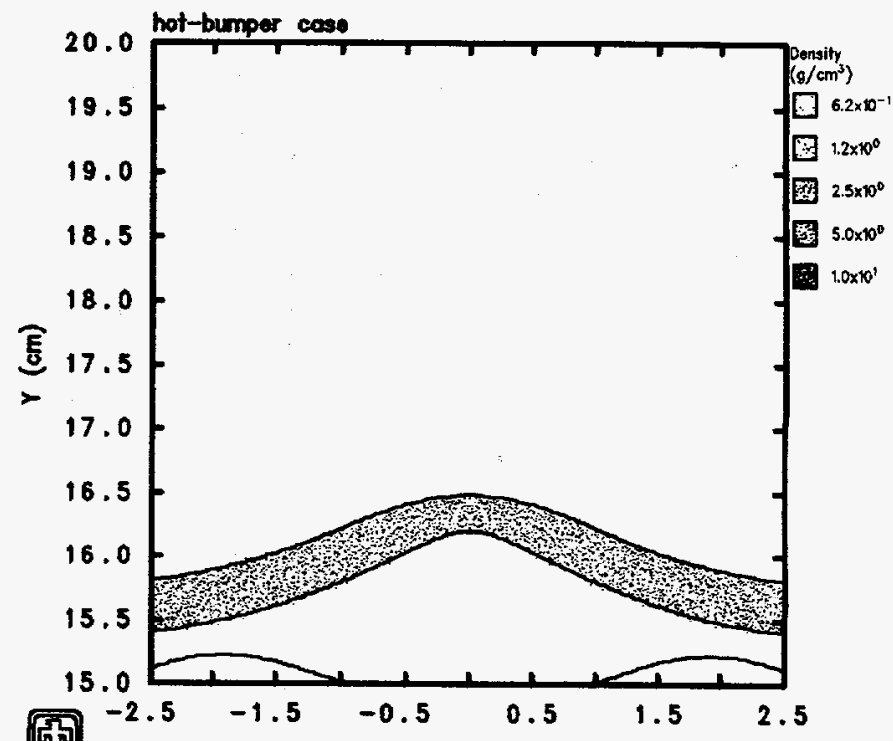

[1] $20 \mathrm{C}$ Block 1

(TM EOS) 2DC CTH XW TIALV PLATE $9.66 \mathrm{KM} / \mathrm{s}$ ON HOT 29MLI-THLVV AUJBLV 01/21/93 09:58:12 CTH 4057 Time $=3.5014 \times 10^{-3}$

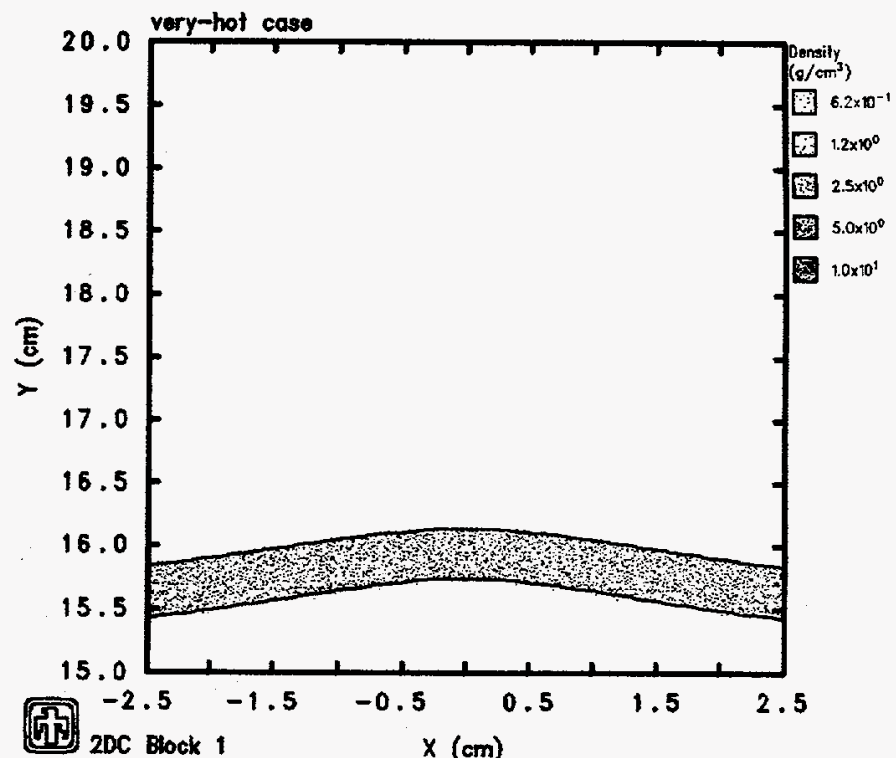

(TMM EOS) 2DC CTH XNG VHOT TIALV PLATE 9,66KM/S ON VHOT 29MIL-TIALI AHJCXY 01/09/93 08:43:34 CTH 4356 Timo $=3.50065 \times 0^{-5}$

Figure 5.1.4. Backwall Configuration at $35 \mu \mathrm{s}$ for Base Case Calculation (upper left), "Hot-Bumper" (upper right), "Hot" (lower left) and "Very-Hot" (lower right) Initial Temperature Variations 

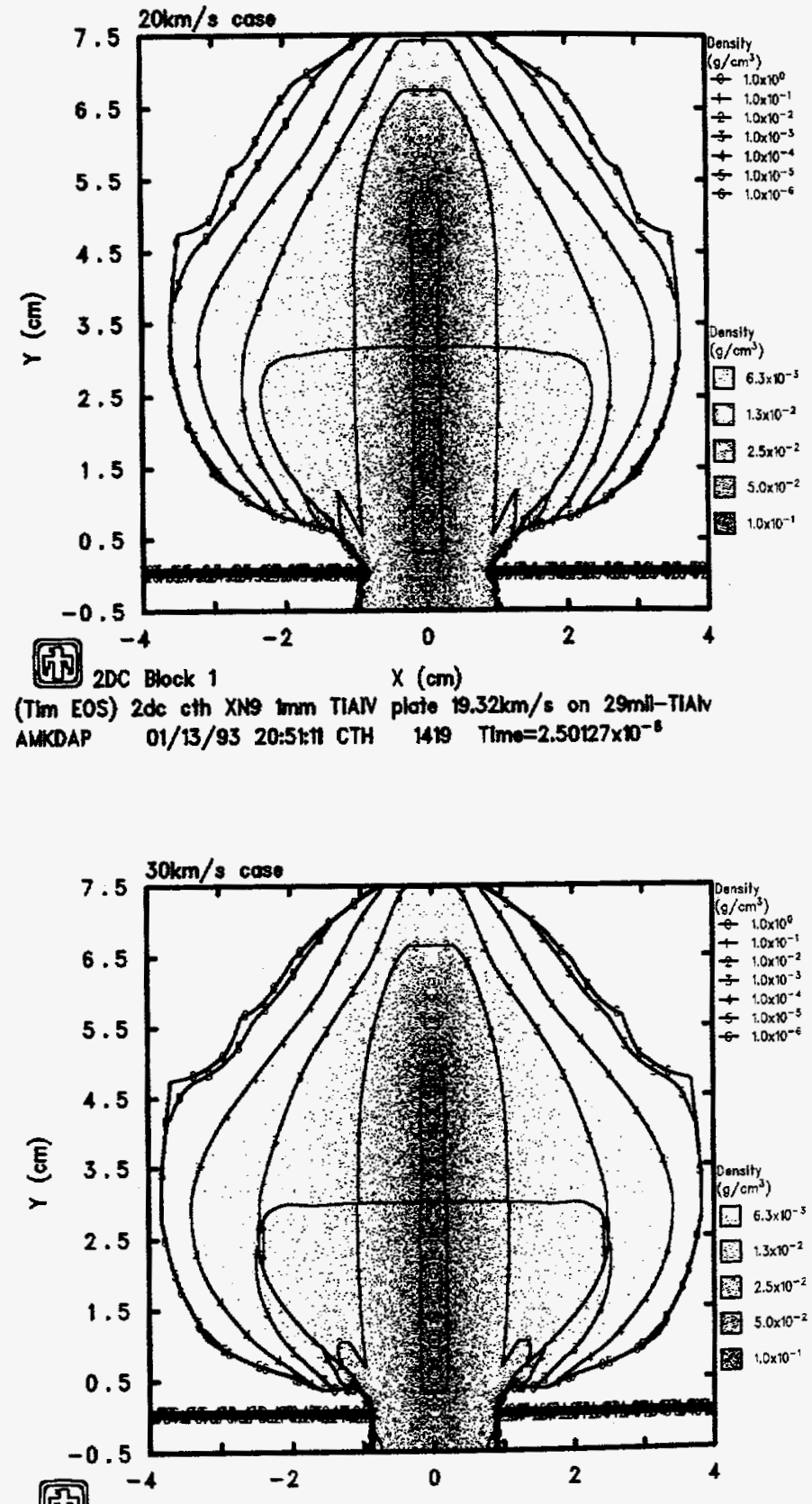

[170 $20 \mathrm{C}$ Block 1

(Tim EOS) $2 \mathrm{dc}$ cth XN9 $\mathrm{lmm}$ TiANV plate $28.98 \mathrm{~km} / \mathrm{s}$ on $29 \mathrm{mil}-T i A l v$

AOLADH $01 / 16 / 93$ 06:43:33 CTH 1413 Time $=1.60015 \times 10^{-6}$

Figure 5.2.1. Debris Cloud at $2.5 \mu \mathrm{s}$ for $20 \mathrm{~km} / \mathrm{s}$ Impact (top) and at $1.6 \mu \mathrm{s}$ for $30 \mathrm{~km} / \mathrm{s}$ Impact (bottom) 

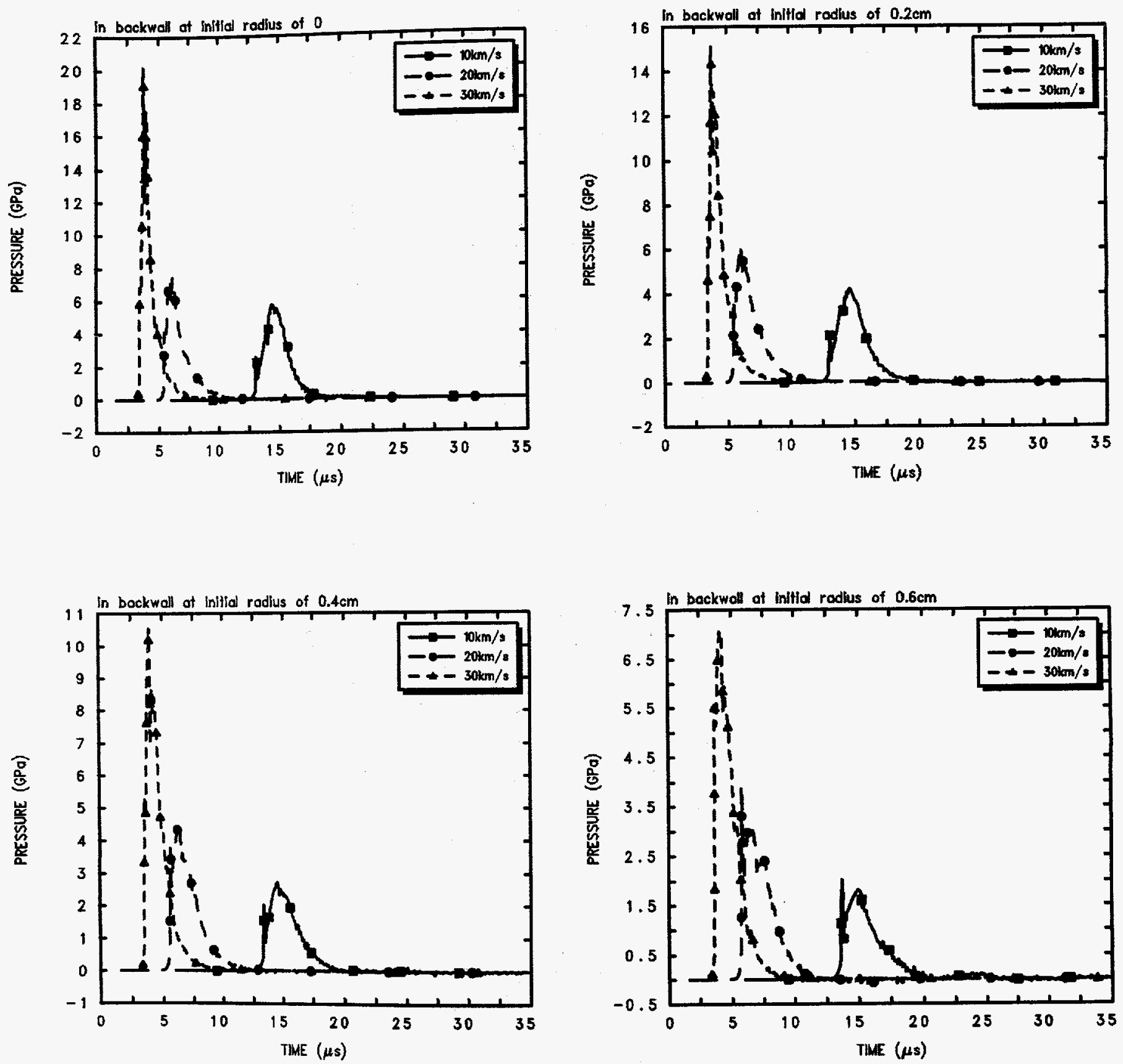

Figure 5.2.2. Pressure on Backwall at Radial Distance of 0 (upper left), $0.2 \mathrm{~cm}$ (upper right), $0.4 \mathrm{~cm}$ (lower left) and $0.6 \mathrm{~cm}$ (lower right) for Base Case Calculation and Impact-Velocity Variations 

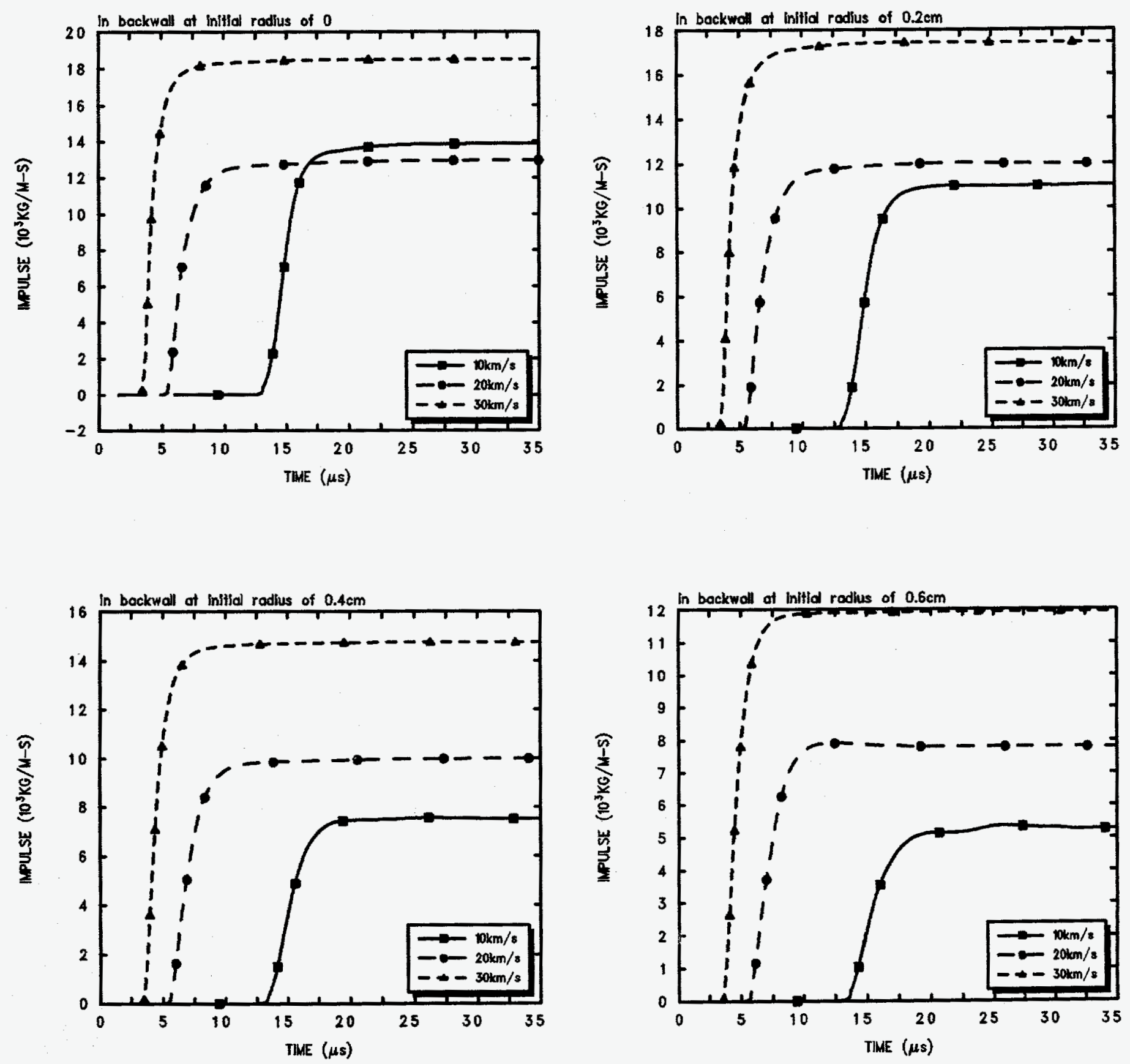

Figure 5.2.3. Impulse on Backwall at Radial Distance of 0 (upper left), $0.2 \mathrm{~cm}$ (upper right), $0.4 \mathrm{~cm}$ (lower left) and $0.6 \mathrm{~cm}$ (lower right) for Base Case Calculation and Impact-Velocity Variations 
and $\sim 30 \mathrm{~km} / \mathrm{s}$, as illustrated in Figure 5.2.4, compared to a final hole diameter of $1.25 \mathrm{~cm}$ predicted in the base case analysis and shown in Figure 4.5. The results of the computational simulations are not surprising considering that the kinetic energy of the projectile is 4 and 9 times the kinetic energy of the basecase projectile.

\subsection{Bumper Material Variations}

Figure 5.3.1 shows the debris cloud structures predicted at $5 \mu$ s assuming equal-mass (i.e., equal areal density) bumper shields made of cadmium and plexiglass instead of titanium alloy. At the time shown, the debris cloud produced by impact with a thin, high-density, cadmium bumper has propagated slightly further both radially and axially and is slightly more spherical in shape than the debris cloud in the base case analysis; the debris cloud produced by impact with a thick, low-density, plexiglass shield has propagated much further axially and is much more elongated. With the cadmium shield, $\sim 55 \%$ of the flier material is vapor at this time (compared to $\sim 50 \%$ in the base case). With the plexiglass bumper, almost all of the flier material is molten by this time.

The more-rapidly expanding debris cloud generated by impact with a plexiglass bumper reaches the backwall earliest, while the leading edges of debris clouds generated by impacts with titanium and with cadmium shields arrive at about the same time, as shown in Figures 5.3.2 and 5.3.3 for typical points in the backwall. All of these debris clouds have enough concentrated kinetic energy to rupture the backwall, with the hole size roughly proportional to the impulse loading delivered to the backwall in each case (as would be expected).

The final configuration of the backwall in these two cases is shown in Figure 5.3.4. The diameter of the resulting hole was predicted to be $1.75 \mathrm{~cm}$ and $1.05 \mathrm{~cm}$, respectively, for the cadmium and plexiglass bumper shields, compared to a final hole diameter of $1.25 \mathrm{~cm}$ in the base case analysis. There appears to be a distinct correlation of the hole size with the density of the bumper material used in these studies. These concepts need to be evaluated further experimentally and theoretically. 


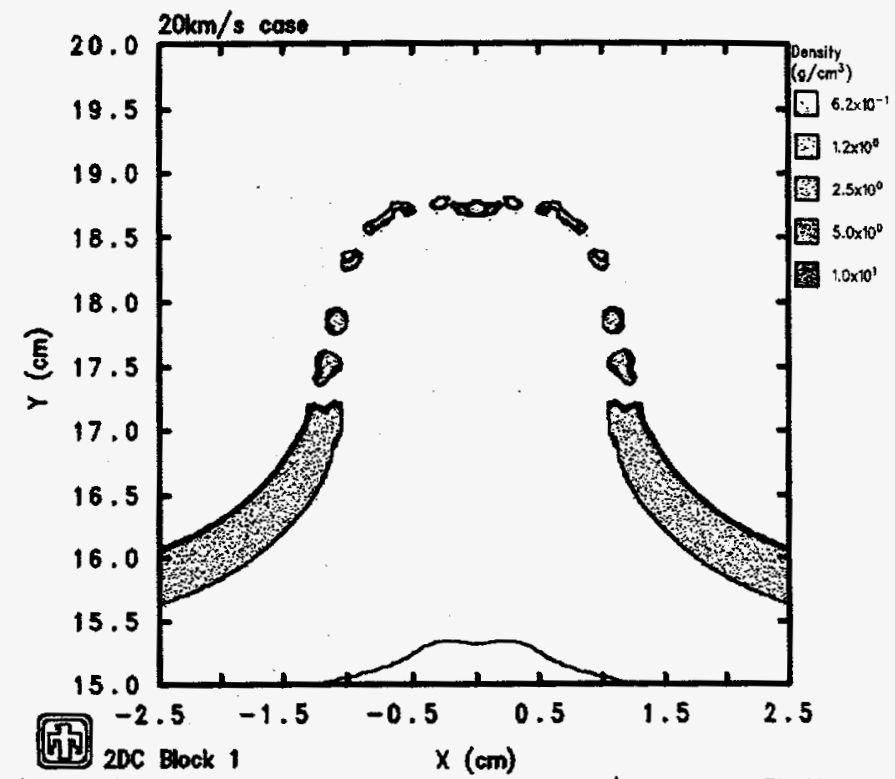

(TN EOS) 2DC CTH XNO IN TIALV PLATE 19.32XN/S ON 29MM-TIALV ASLEQU 0t/20/93 04:00:19 CTH 5897 Tmo $=3.50034 \times 10^{-5}$

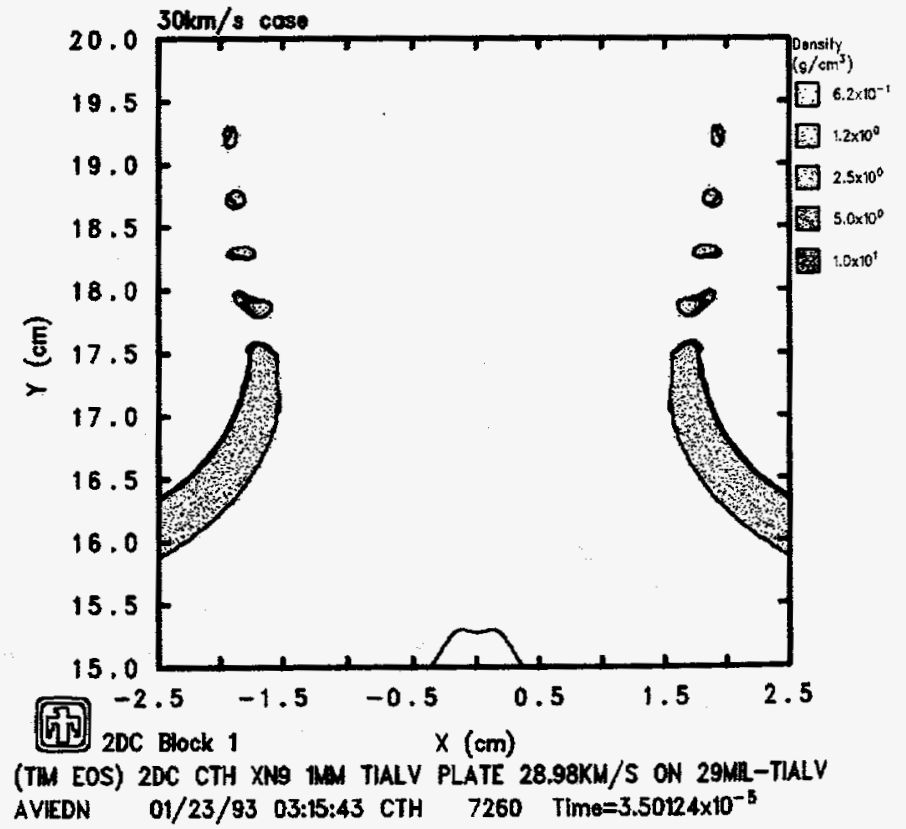

Figure 5.2.4. Backwall Configuration at $35 \mu \mathrm{s}$ for $20 \mathrm{~km} / \mathrm{s}$ Impact (top) and for $30 \mathrm{~km} / \mathrm{s}$ Impact (bottom) 

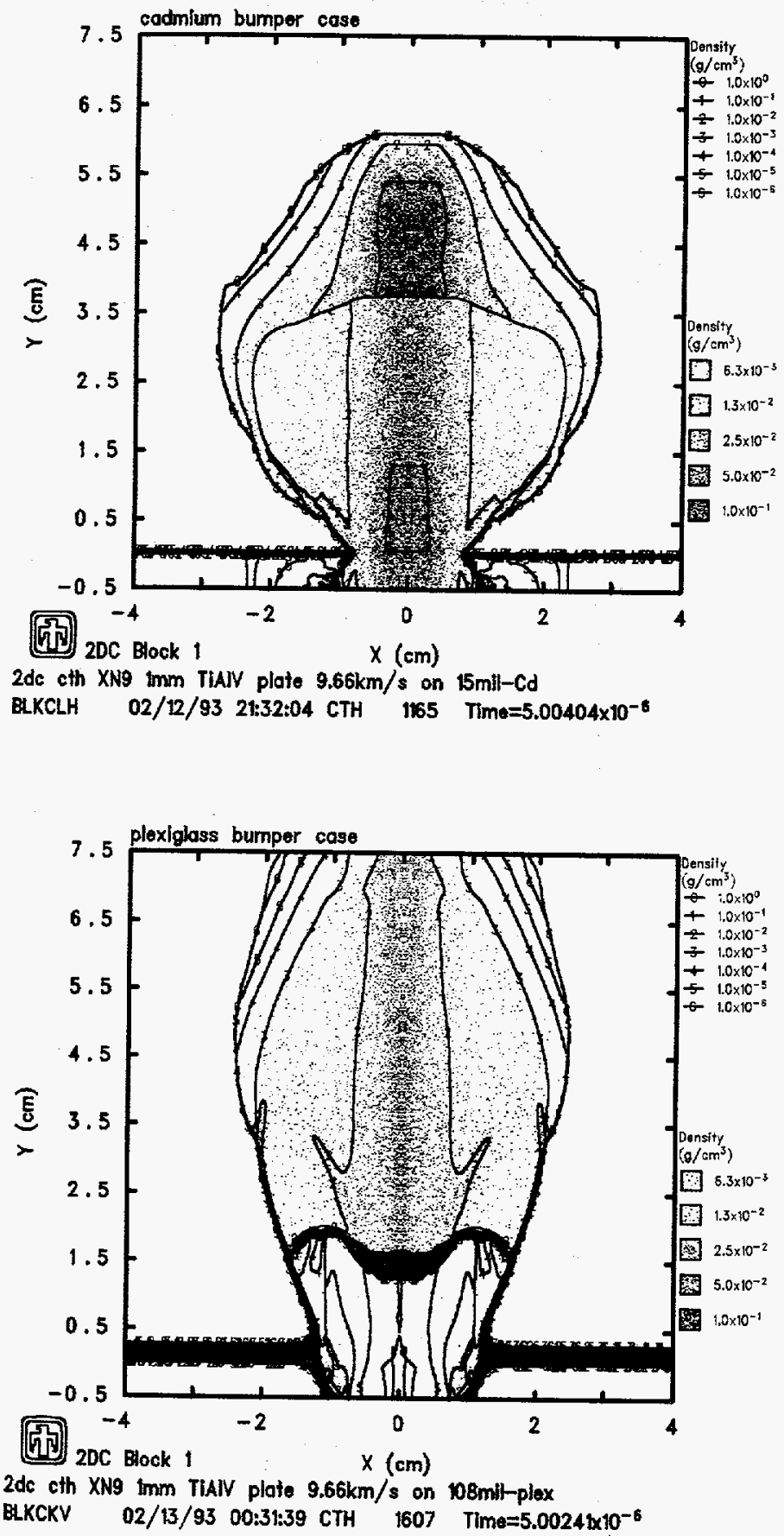

Figure 5.3.1. Debris Cloud at $5 \mu$ s for Cadmium Bumper Shield (top) and for Plastic Bumper Shield (bottom) 

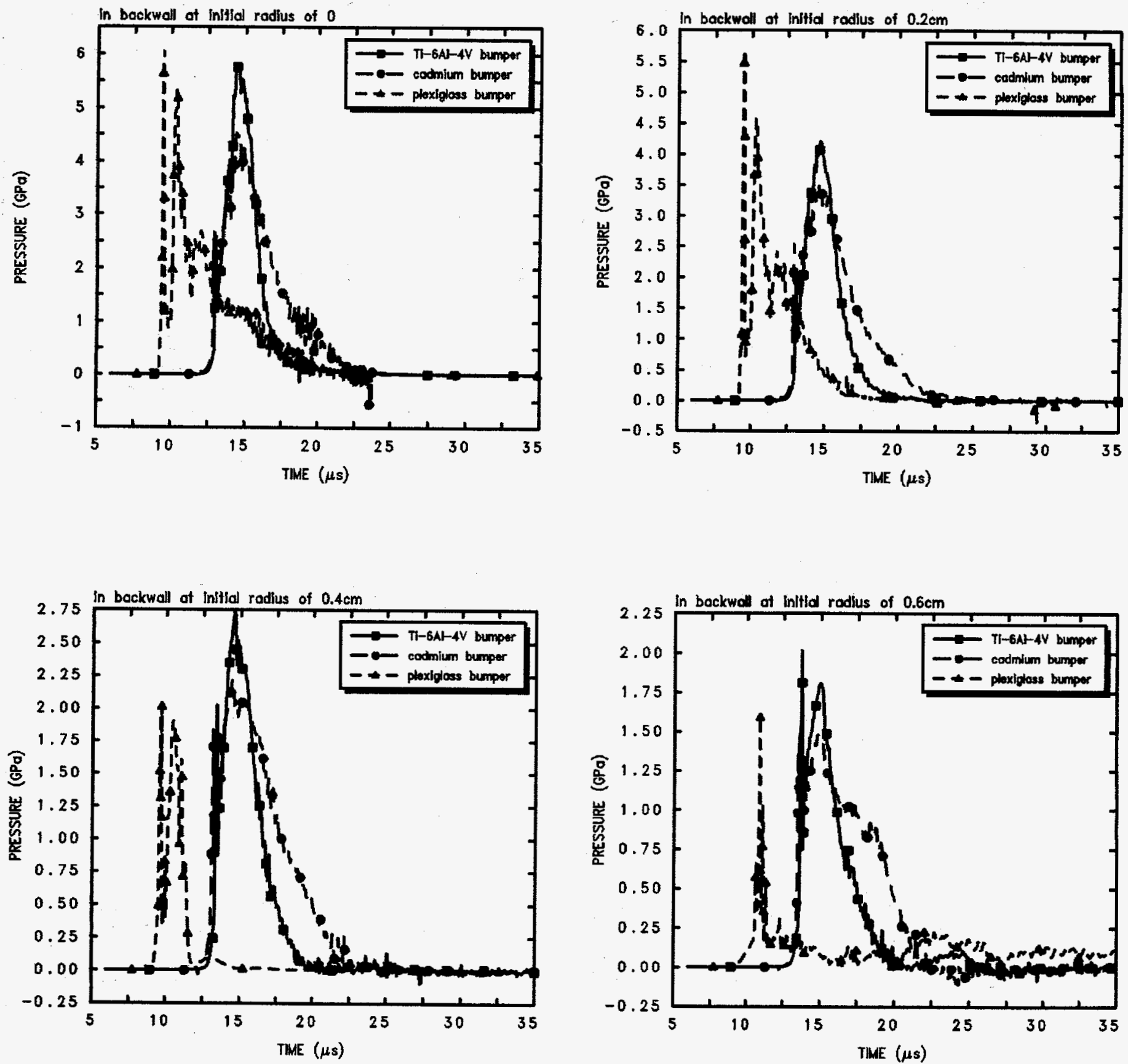

Figure 5.3.2. Pressure on Backwall at Radial Distance of 0 (upper left), $0.2 \mathrm{~cm}$ (upper right), $0.4 \mathrm{~cm}$ (lower left) and $0.6 \mathrm{~cm}$ (lower right) for Base Case Calculation and Bumper-Material Variations 

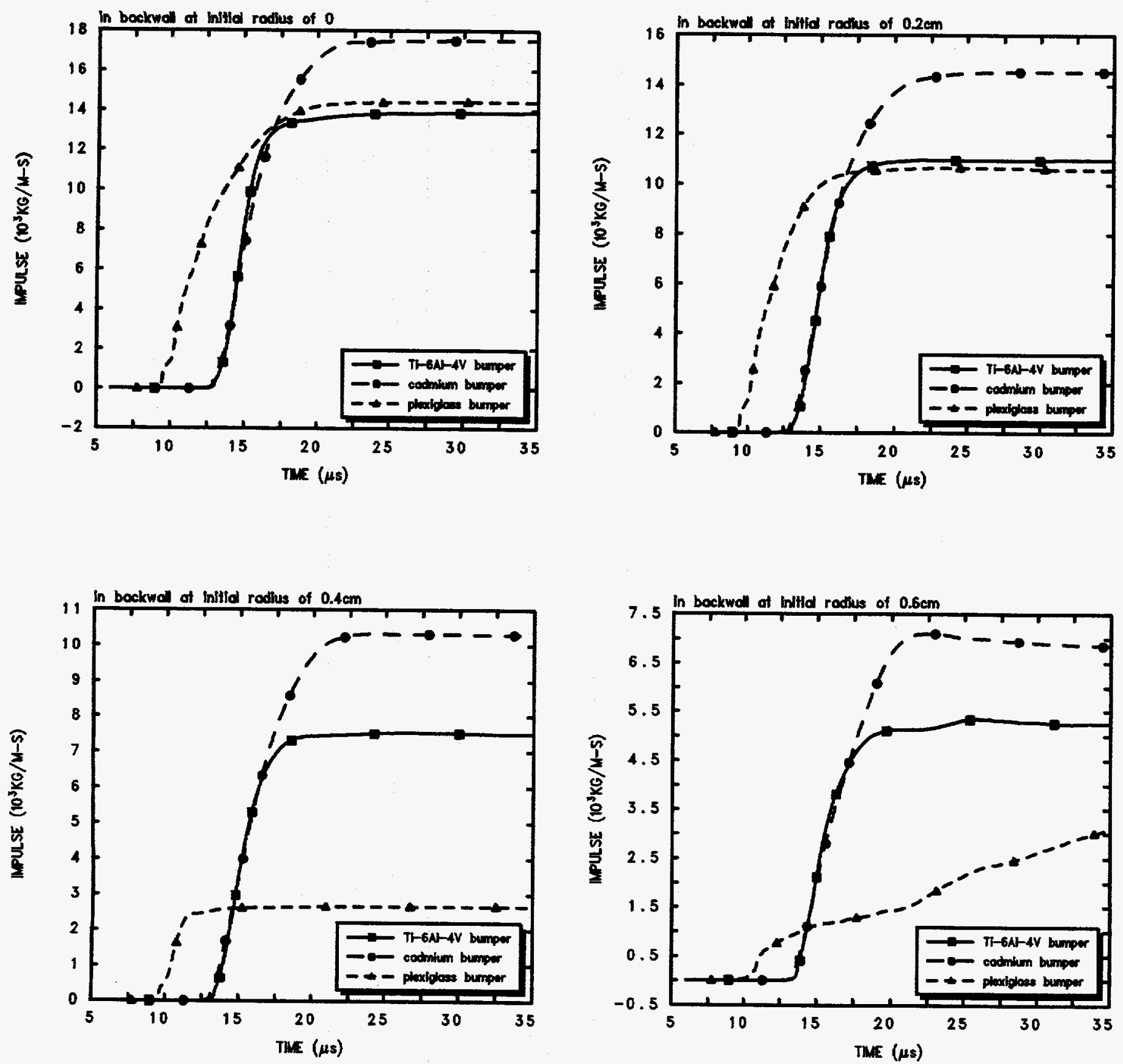

Figure 5.3.3. Impulse on Backwall at Radial Distance of 0 (upper left), $0.2 \mathrm{~cm}$ (upper right), $0.4 \mathrm{~cm}$ (lower left) and $0.6 \mathrm{~cm}$ (lower right) for Base Case Calculation and Bumper-Material Variations 

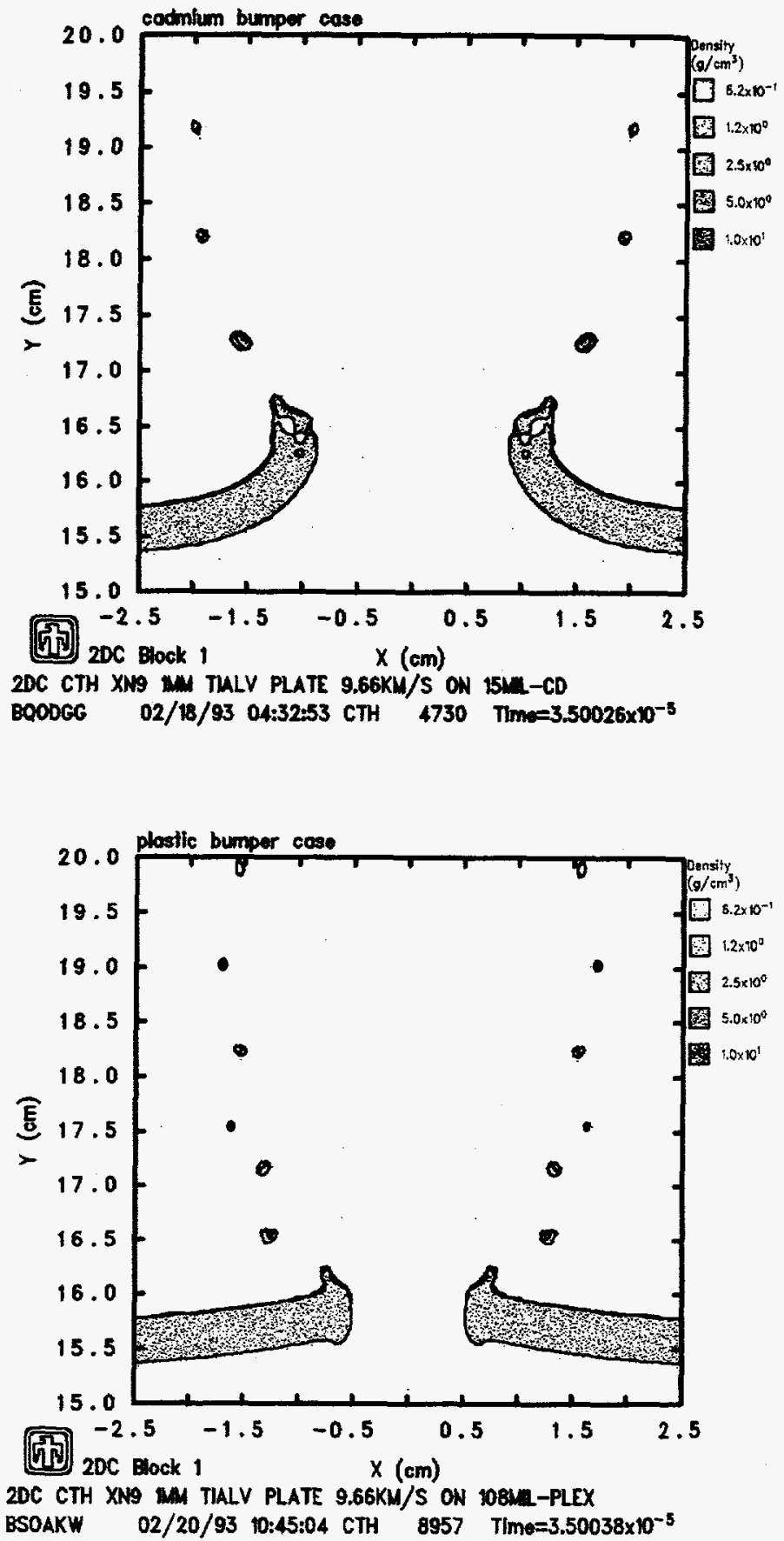

Figure 5.3.4. Backwall Configuration at $35 \mu$ s for Cadmium Bumper Shield (top) and for Plastic Bumper Shield (bottom) 


\section{Summary and Conclusions}

A series of calculations using the finite difference code CTH has been used to evaluate the effect of phase change (i.e., higher concentrations of vapor) in a debris cloud and subsequent impact on a backwall structure. There is considerable speculation suggesting that the presence of an increased concentration of vapor states in a hypervelocity debris cloud would be sufficient to prevent the rupture of a backwall structure. The present study indicates that merely having an increased concentration of vapor in a debris cloud is not adequate to prevent the rupture of the structure upon which it impinges.

The use of these calculations is validated by comparing the results of CTH calculations with an experiment in which a titanium-alloy flier plate impacts a cold (room temperature) bumper sheet at $9.7 \mathrm{~km} / \mathrm{s}$. The propagation characteristics of the resulting debris cloud determined calculationally agrees well qualitatively with the measured debris cloud and is noted to rupture a backwall structure both in the calculation and in the experiment.

Higher concentrations of vapor were achieved by increasing the initial temperature of the bumper material and the impactor at the same impact velocity of $\sim 10 \mathrm{~km} / \mathrm{s}$. The results of these calculations may be summarized as follows:

- It is merely sufficient to increase the temperature of the bumper plate close to its melt temperature to prevent the rupture of the backwall structure.

- The debris cloud is sufficiently dispersed both spatially and temporally to result in distributing the impact load over a wider surface and a longer time frame.

Higher concentrations of vapor also can be achieved by increasing the initial impactor velocity to $\sim 20$ and $\sim 30 \mathrm{~km} / \mathrm{s}$. The results of these calculations may be summarized as follows:

- The kinetic energy of the impacting projectile is now a factor of 4 and 9 times the kinetic energy of the projectile travelling at $\sim 10 \mathrm{~km} / \mathrm{s}$.

- The resulting debris cloud propagates at much faster speeds when compared to the base case at $10 \mathrm{~km} / \mathrm{s}$, resulting in a higher impulsive loading on the backwall structure located at the same standoff distance from the bumper.

- Since the debris cloud does not have enough time and/or space to disperse adequately before impinging on the backwall, it results in rupturing the structure.

In another set of calculations, higher concentrations of debris cloud vapor were obtained through the selection of low melting point bumper materials such as cadmium and a plastic plexiglass polymethylmethacrylate. In each case, the thickness of the bumper sheet was varied to ensure the same areal density as the base case. Results of these calculations may be highlighted as follows: 
- Although a higher concentration of vaporized states do exist in the debris cloud, the backwall structure indeed ruptures upon loading.

- The hole size in the backwall appears to correlate with the density/impedance of the bumper material.

- This appears to be the result of a larger impulsive loading on the backwall structure when higher impedance materials are used as bumper sheets.

Based on this study it would appear that lower density materials would perform better as bumper shield materials when compared to higher density materials, for comparable masses. These computational results in each instance need to be evaluated further experimentally. 


\section{Bibliography}

[1] D. J. Kessler, Adv. Space Res. 5 (1985) 3.

[2] D. J. Kessler, R. C. Reynolds, P. D. Anz-Meador, NASA Technical Memorandum 100471 (1989).

[3] B. G. Cour-Palais, AIAA Paper No. 69-372, April 1969.

[4] J. P. D. Wilkinson, AIAA Journal, 7, (1969) 1937.

[5] E. S. Hertel, L. C. Chhabildas, S. A. Hill, "Whipple Bumper Shield Simulations", in "Shock Waves in Condensed Matter - 1991", Eds. S. C. Schmidt, J. W. Forbes, R. D. Dick, Elsevier Science Publishers B. V., 1992.

[6] L. C. Chhabildas, L. M. Barker, J. R. Asay, T. G. Trucano, G. I. Kerley, J. E. Dunn, "Launch Capabilities to Over $10 \mathrm{~km} / \mathrm{s}$ ", in "Shock Waves in Condensed Matter 1991", Eds. S. C. Schmidt, J. W. Forbes, R. D. Dick, Elsevier Science Publishers B. V., 1992.

[7] L. C. Chhabildas, L. M. Barker, J. R. Asay, T. G. Trucano, G. I. Kerley, SAND910657, Sandia National Laboratories, May 1991.

[8] L. C. Chhabildas, J. E. Dunn, W. D. Reinhart, J. M. Miller, Intnl. J. Impact Engng., V14, 1993.

[9] L. C. Chhabildas, E. S. Hertel, S. A. Hill, "Whipple Bumper Shield Results and CTH Simulations at Velocities in Excess of $10 \mathrm{~km} / \mathrm{s}$ ", Intnl. J. Impact Engng., V14, 1993.

[10] J. M. McGlaun, S. L. Thompson, L. N. Kmetyk, and M. G. Elrick, "A Brief Description of the Three-Dimensional Shock Wave Physics Code CTH", SAND89-0607, Sandia National Laboratories, July 1990.

[11] L. C. Chhabildas, E. S. Hertel, S. A. Hill, "Whipple Bumper Shield Tests at Over $10 \mathrm{~km} / \mathrm{s}$ ", in "Shock Waves in Condensed Matter - 1991", Eds. S. C. Schmidt, J. W. Forbes, R. D. Dick, Elsevier Science Publishers B. V., 1992.

[12] L. C. Chhabildas, M. B. Boslough, "Experimental Technique to Launch Flier-Plates Representing Orbital Debris to Hypervelocities", Proceedings, 1993 SPIE Conference, Orlando, Florida, April 1993 (to be published).

[13] L. C. Chhabildas, E. S. Hertel, S. A. Hill, "Experimental and Numerical Simulations of Orbital Debris Impact on a Simple Whipple Bumper Shield", Proceedings, Hypervelocity Impact Symposium - 1991, University of Kent at Canterbury, Kent, UK, ed. J. A. M. McDonnel. 
[14] J. A. Ang, L. C. Chhabildas, B. G. Cour-Palais, E. C. Christiansen, J. L. Crews, "Evaluation of Whipple Bumper Shields at 7 and $10 \mathrm{~km} / \mathrm{s}$ ", AIAA Paper 92-1590, Space Programs and Technology Conference, 1992.

[15] M. B. Boslough, J. A. Ang, L. C. Chhabildas, B. G. Cour-Palais, E. C. Christiansen, J. L. Crews, W. D. Reinhart, C. A. Hall, "Hypervelocity Testing of Advanced Shielding Concepts for Spacecraft Against Impacts to $10 \mathrm{~km} . \mathrm{s}$, Int. J. Impact Engng., Vol. 14, 1993.

[16] L. C. Chhabildas, E. S. Hertel, "Orbital Debris Impact on a Simple Whipple Bumper Shield", Aerospace Testing Seminar Series, Proceedings, Institute of Environmental Series, 1993.

[17] E. S. Hertel, L. C. Chhabildas, "Computational Determination of the Ballistic Limits for a Simple Whipple Bumper Shield", Proceedings, Hypervelocity Impact Symposium - 1991, University of Kent at Canterbury, Kent, UK, ed. J. A. M. McDonnel.

[18] L. C. Chhabildas, M. B. Boslough, "Experimental Technique to Simulate Orbital Debris Impact on Space Shields at Impact Velocities over $10 \mathrm{~km} / \mathrm{s}$ ", Proceedings, First European Space Conference on Space Debris, Darmstadt, Germany, April 5-7, 1993.

[19] S. L. Thompson, "ANEOS Analytic Equations of State for Shock Physics Codes Input Manual", SAND89-2951, Sandia National Laboratories, March 1990.

[20] T. G. Trucano, "EOS Comparisons", Memo to L. N. Kmetyk dated June 29, 1992. 


\section{A Bumper-Impact Input Deck}

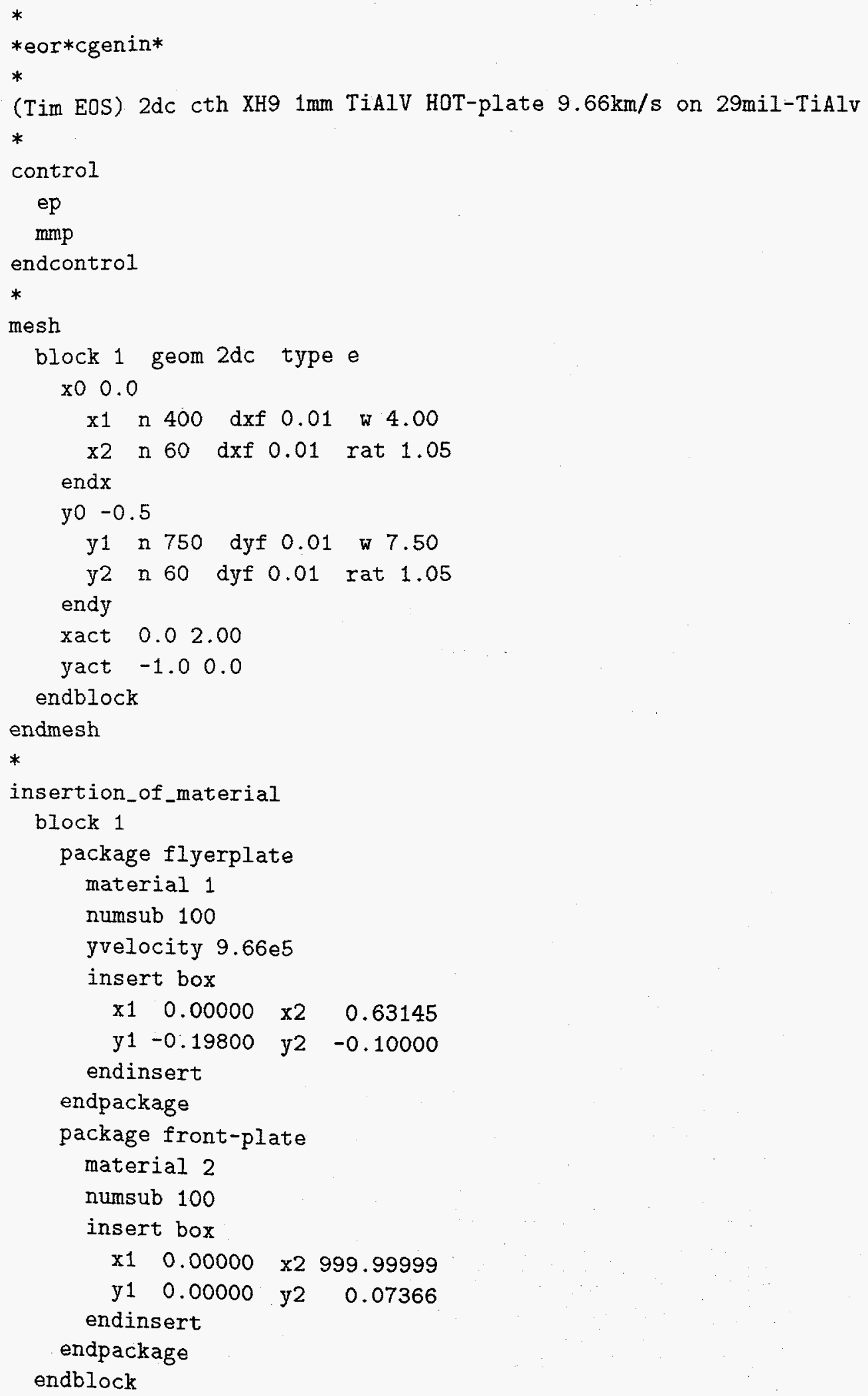




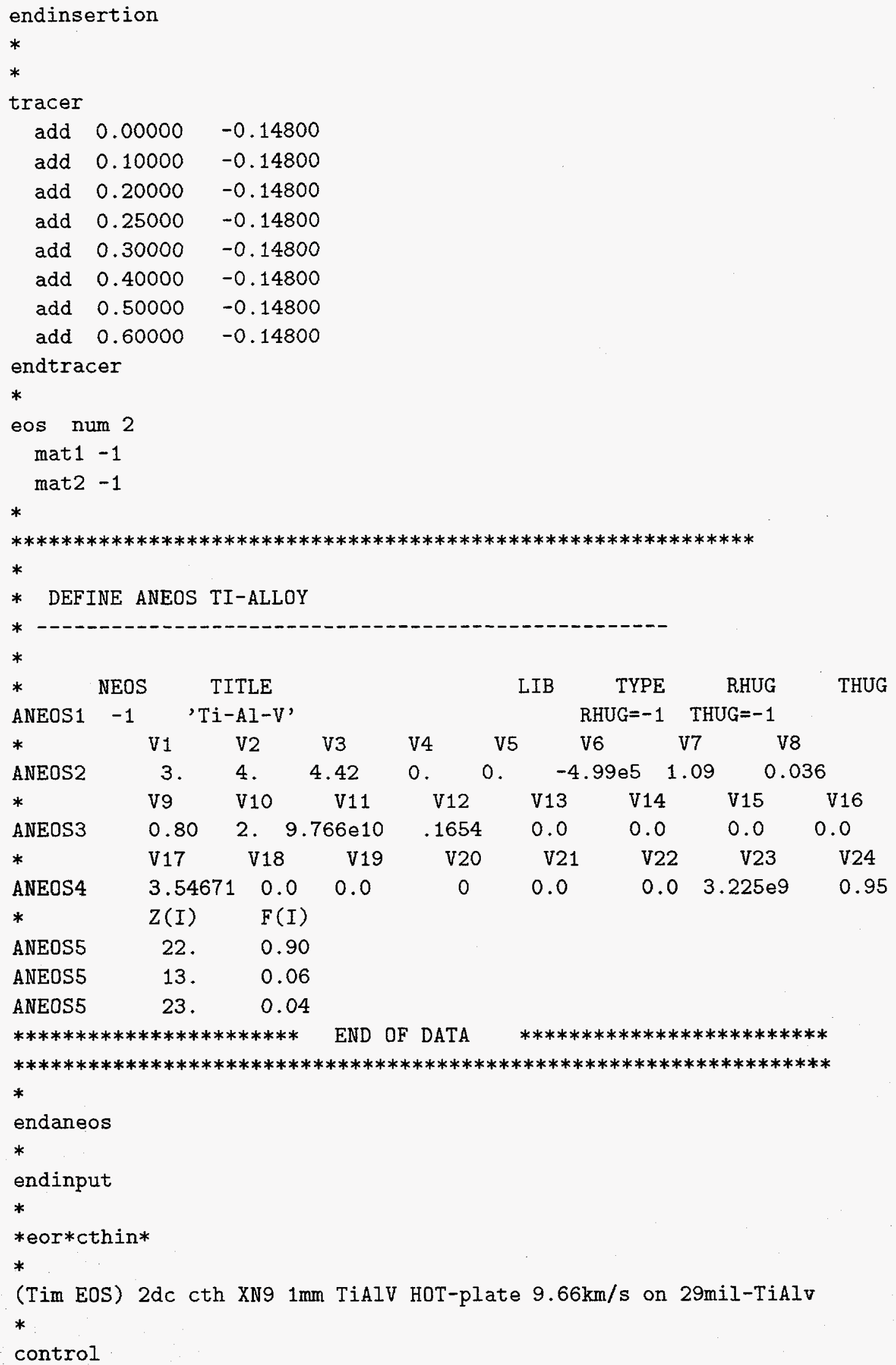




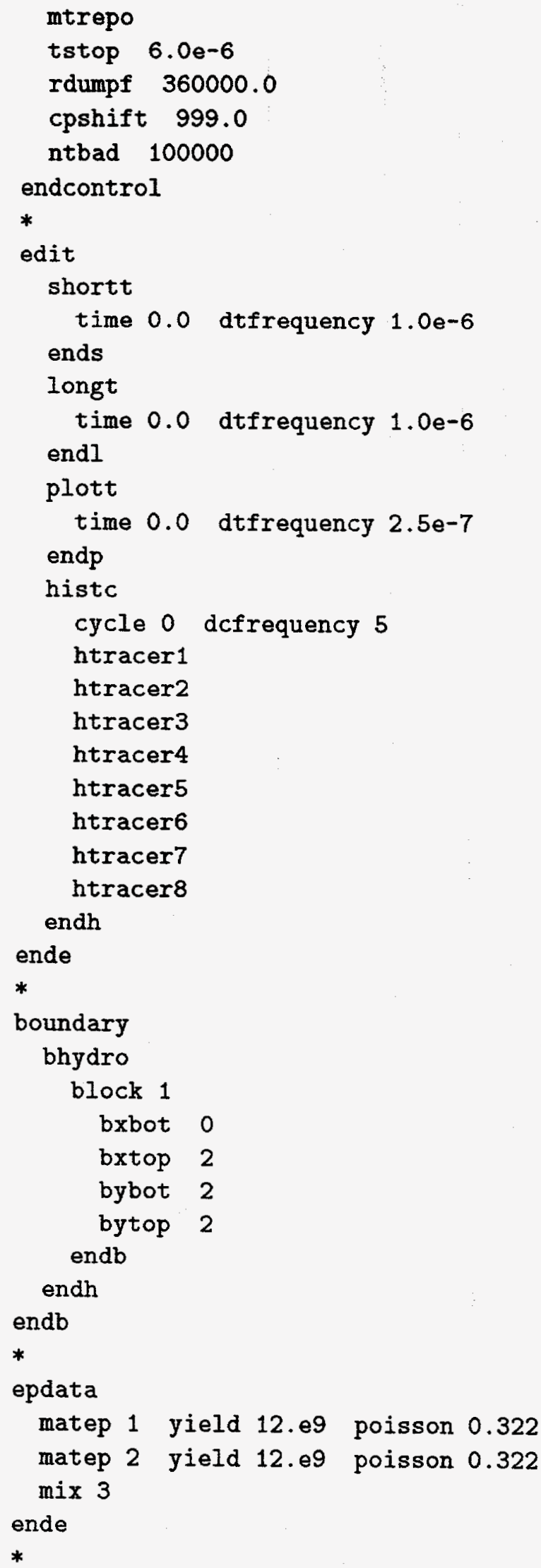




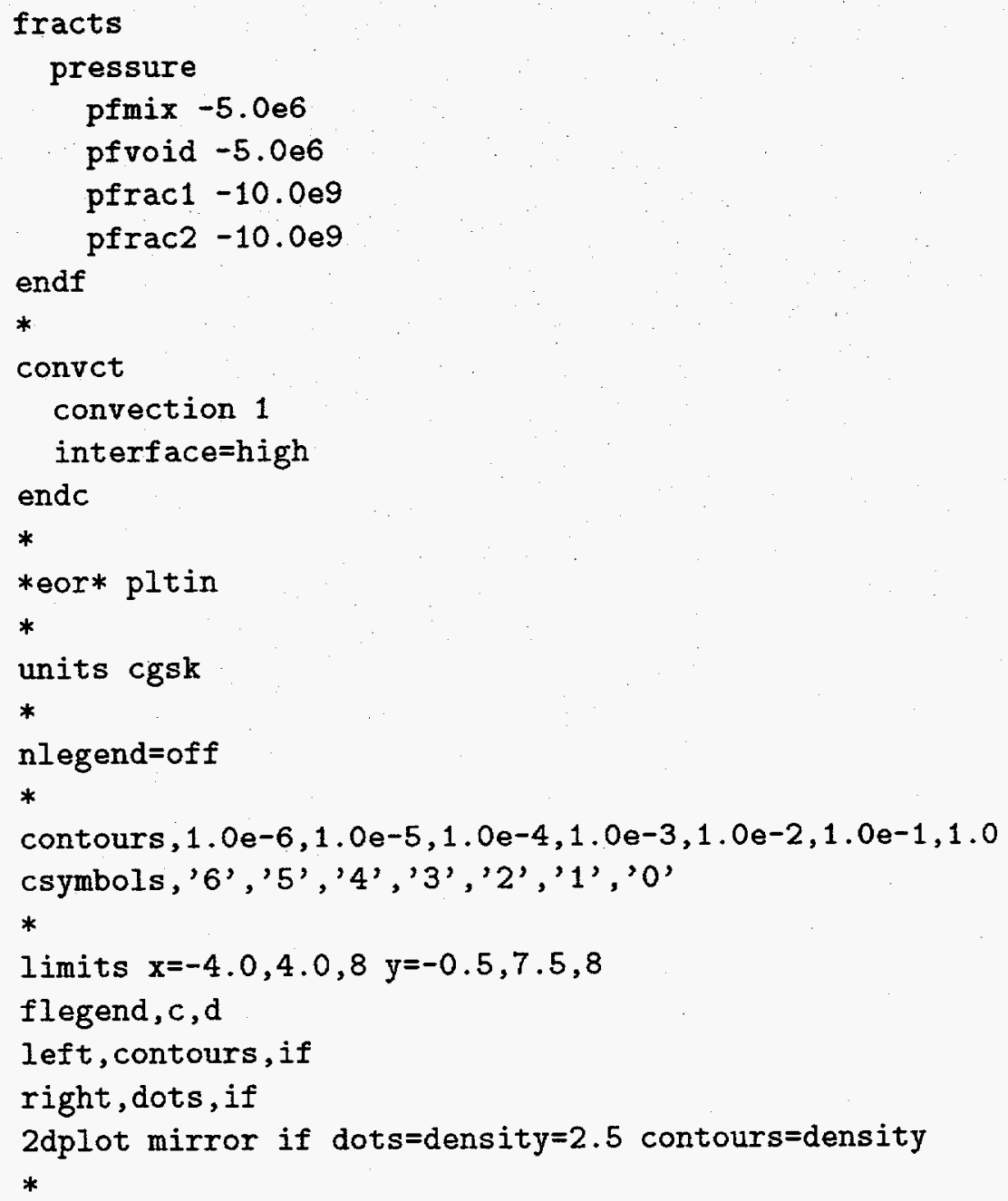




\section{B Backwall-Impact Input Deck}

*

2d cth rezone debris cloud

*

prerezone

file='rsctt'

ofile='rezout'

numsub $=25$

time $=6.0 e-6$

geom

$\operatorname{map}=2 \mathrm{~d}$ to $2 \mathrm{~d}$

endg

endp

.

*

*eor*rezin*

*

(Tim EOS) $2 \mathrm{dc}$ cth XH9 $1 \mathrm{~mm}$ TiAlV plate $9.66 \mathrm{~km} / \mathrm{s}$ on $29 \mathrm{mil}-\mathrm{TiAlv}$

*

control

ep

mmp

time $6.0 e^{-6}$

endcontrol

*

mesh

block 1 geom 2dc type e

$\mathrm{x} 00.0$

$x 1$ n 100 dxf 0.04 4.00

$x 2 n 50$ dxf 0.04 rat 1.05

end $\mathrm{x}$

yo -0.5

y1 $n 475$ dyf 0.04 w 19.0

y2 $\mathrm{n} 25$ dyf 0.04 rat 1.05

endy

xact 0.03 .00

yact -1.08 .0$

endblock

endmesh

*

rezone

file= 'rezout'

endr

*

insertion_of_material

block 1 


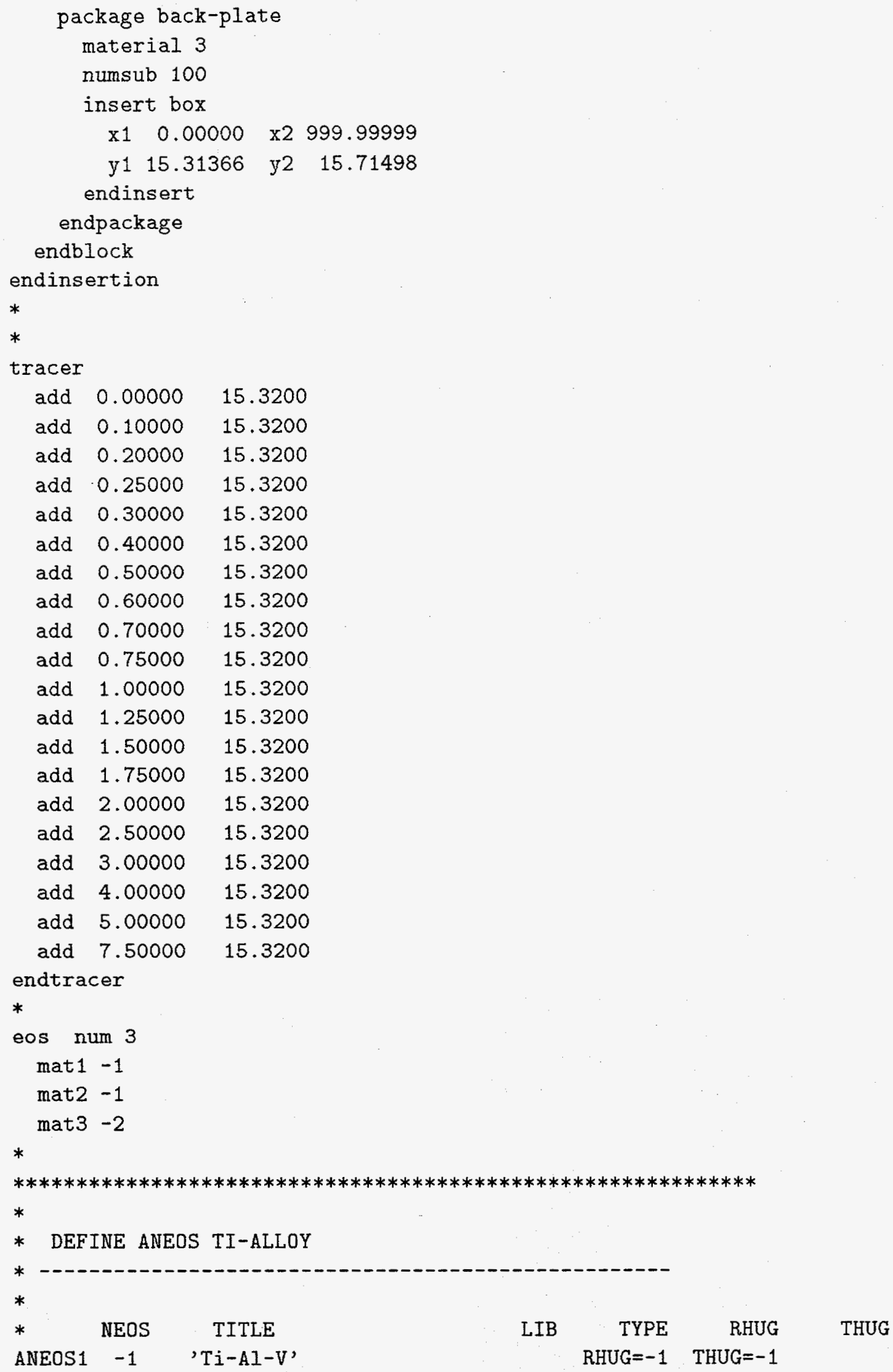




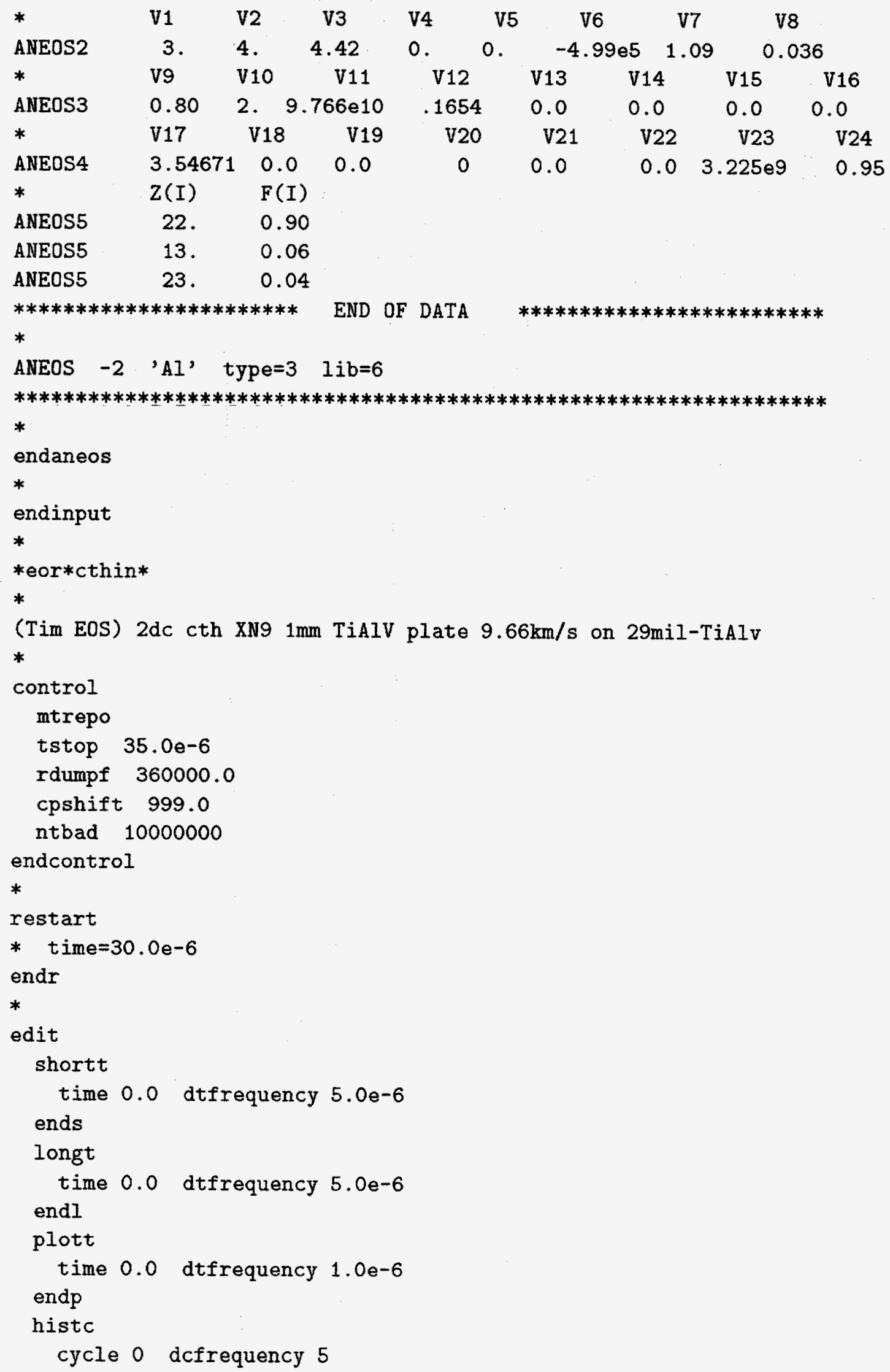




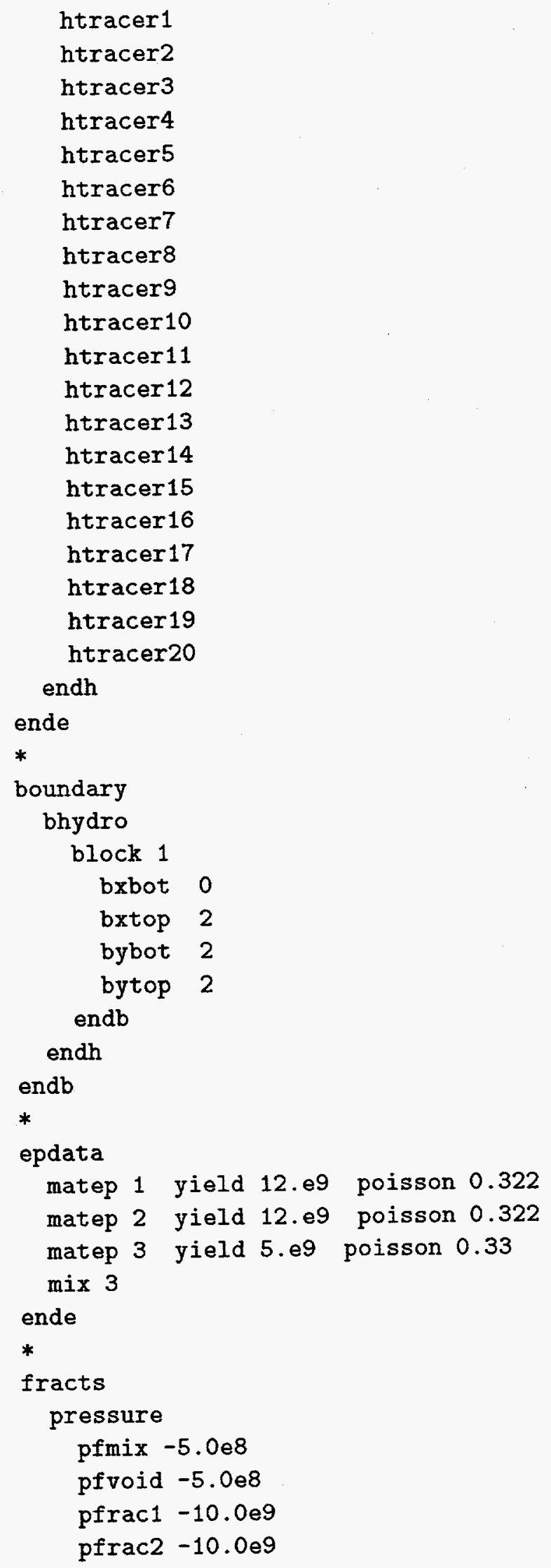




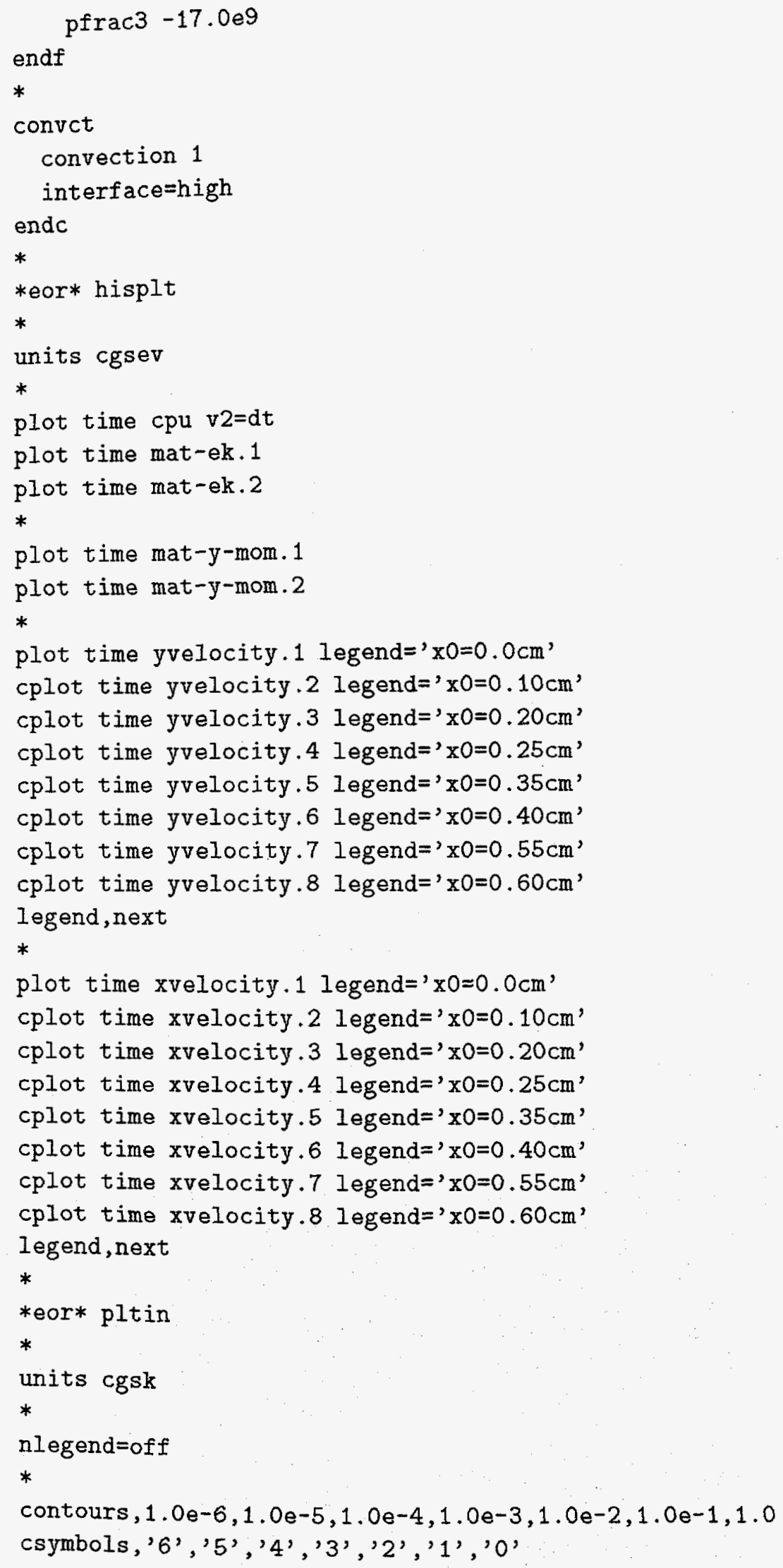


limits $x=-4.0,4.0,8 \quad y=-0.5,7.5,8$

flegend, $c, d$

left, contours, if

right, dots, if

2dplot mirror if dots $=$ density $=2.5$ contours $=$ density

* 
DISTRIBUTION:

EXTERNAL DISTRIBUTION

Anderson, Charles E. (4)

Southwest Research Institute

P.O. Drawer 28510

San Antonio, TX 78284

Ari, Nasit (5)

Kaman Sciences Corporation

1500 Garden of the Gods Road

P. O. Box 7463

Colorado Springs, CO 80933

Barker, Lyn

13229 Circulo Largo NE

Albuquerque, NM 87112

Kocher, Robert (3)

Defense Advanced Research Projects

Agency

3701 North Fairfax Drive

Arlington, VA 22203-1714

Attn: R. Kocher, J. Beno, J. Richardson

Bradley, Kenneth R.

Defense Nuclear Agency

Washington, DC 20305-1000

Christiansen, Eric L.

NASA Johnson Space Center

Space Science Branch - Mail Code SN3

Houston, TX 77058

Connell, John(2)

DNA/SPSP

6801 Telegraph Rd.

Alexandria, VA 22310

Attn: J. Connell \& T. Frederickson

Crews, Jeanne L.

NASA Johnson Space Center

Space Sciences Branch - Mail Code SN3

Houston, TX 77058
Foster, Joseph C.

Wright Laboratory

WL/MNMW

Eglin AFB, FL 32542-5434

Fry, Mark

SAIC/New York

8 West 40th Street

14 Floor

New York, New York 10018

Holsapple, Keith A.

Department of Aeronautics and

Astronautics FS10

The University of Washington

FS10

Seattle, WA 98195

Hough, Gary

Aerophysics Research Facility

University of Alabama at Huntsville

Huntsville, AL 35899

Hunt, Ron(3)

Wright Laboratory

WL/MNSA

Eglin AFB, FL 32542-5434

Attn: J. Bailey, R. Hunt, and B. Patterson

Johnson, Gordon R.

Alliant Techsystems Inc.

7225 Northland Dr.

Brooklyn Park, MN 55428

Kimsey, Kent

U.S. Army Ballistic Research Laboratory

Attn.: SLCBR-TB-P

Aberdeen Proving Ground MD 21005-

5066

Orphal, Dennis L.(2)

California Research \& Technology, Inc.

5117 Johnson Dr.

Pleasanton, CA 94588

Attn: D.L. Orphal \& P. N. Schneidewind 
Steinberg, D. J.

4174 Pomona Way

Livermore, CA 94550

Wilbeck, James

Kaman Sciences Corporation

600 Boulevard South, Suite 208

P. O. Box 2486

Huntsville, AL 35804-2486

Los Alamos National Laboratory (20)

Mail Station 5000

P.O. Box 1663

Los Alamos, NM 87545

Attn: T. F. Adams, MS F663

Attn: B. I. Bennett, MS B221

Attn: M. W. Burkett, MS F663

Attn: R. A. Clark, MS F663

Attn: J. K. Dienes, MS B221

Attn: R. P. Godwin, MS F663

Attn: F. Harlow, MS B216

Attn: W. B. Harvey, MS F663

Attn: B. L. Holian, MS B268

Attn: K. S. Holian, MS F663

Attn: J. W. Hopson, MS B216

Attn: H. Horak, MS G780

Attn: N. L. Johnson, MS B216

Attn: J. F. Kerrisk, MS F663

Attn: D. Mandell, MS F663

Attn: L. G. Margolin, MS C305

Attn: G. H. McCall, MS B218

Attn: J. K. Meier, MS J576

Attn: R. W. Meier, MS G787

Attn: D. Tonks, MS B267

Univeristy of California (7)

Lawrence Livermore National Laboratory 7000 East Ave.

P.O. Box 808

Livermore, CA 94550

Attn: D. W. Baum, MS-L035

Attn: D. E. Burton, MS L-18

Attn: R. B. Christensen, MS L-35

Attn: L. A. Glenn, MS-L200
Attn: N. Holmes, MS-L299

Attn: W. J. Nellis, MS-L299

Attn: R. E. Tipton, MS L-35

SANDIA INTERNAL
MS0321
E. H. Barsis, 1400
MS0819
J. M. McGlaun, 1431
MS0819
K. G. Budge, 1431
MS0819
E. S. Hertel, 1431
MS0819
R. J. Lawrence (5)
MS0819
J. S. Peery, 1431
MS0819
A. C. Robinson, 1431
MS0819
MS0819
T. G. Trucano, 1431
MS0820
MS0820
M. Wong, 1431
P. Yarrington, 1432
MS0820
G. I. Kerley, 1432
MS0820
M. E. Kipp, 1432
MS0821
S. A. Silling, 1432
MS0821
P. L. Stanton, 1433
MS0821
J. A. Ang, 1433
MS0821
MS0821
M. B. Boslough, 1433(5)
MS0821
MS0821
MS0821
MS0821
MS0821
L. C. Chhabildas, 1433 (30)
D. A. Crawford, 1433
M. D. Furnish, 1433
D. E. Grady, 1433
C. A. Hall, 1433
C. H. Konrad, 1433
W. D. Reinhart, 1433
MS0841
MS0836
D. J. McCloskey, 1500
MS0827
C. W. Peterson, 1501
MS0457
P. J. Hommert, 1502
MS0457
D. B. Hayes, 5600
MS0745
J. R. Asay, 5602
MS0745
S. L. Thompson, 6418
MS0899
L. N. Kmetyk, 6418 (10)
MS0619
Technical Library, 7141 (5)
MS9018
Technical Publications, 7151
MS0100
Document Processing for DOE/OSTI, 7613-2 